NBER WORKING PAPER SERIES

\title{
CLO PERFORMANCE
}

\author{
Larry Cordell \\ Michael R. Roberts \\ Michael Schwert
}

Working Paper 29410

http://www.nber.org/papers/w29410

\author{
NATIONAL BUREAU OF ECONOMIC RESEARCH \\ 1050 Massachusetts Avenue \\ Cambridge, MA 02138 \\ October 2021
}

We thank Jeremy Brizzi, Alan Huang, Yilin Huang, Akhtar Shah, and the customer support team at Intex Solutions for their invaluable assistance in constructing the data set for this paper, and Xudong An, Bo Becker, Darrell Duffie, Daniel Green, Fotis Grigoris, John Griffin, Fred Hoffman, Chris James, Arthur Korteweg, Mark Mitchell, Taylor Nadauld, Jordan Nickerson, Greg Nini, Yoshio Nozawa, Matt Plosser, Todd Pulvino, Bill Schwert, Serhan Secmen, Rob Stambaugh, Rene Stulz, Fabrice Tourre, Stephane Verani; seminar participants at the Corporate Finance Virtual Seminar series, Dartmouth College, Federal Reserve Bank of Chicago, Federal Reserve Bank of Philadelphia, Frankfurt School of Finance, London Business School, New York University, Ohio State University, Rutgers University, University of Florida, University of Rochester, Wharton; and conference participants at the SFS Cavalcade, WFA, and NBER Summer Institute for helpful comments. We gratefully acknowledge financial support from the Jacobs Levy Equity Management Center. The views expressed in this paper are those of the authors and do not necessarily reflect the position of the Federal Reserve Bank of Philadelphia or the Federal Reserve System. The views expressed herein are those of the authors and do not necessarily reflect the views of the National Bureau of Economic Research.

NBER working papers are circulated for discussion and comment purposes. They have not been peer-reviewed or been subject to the review by the NBER Board of Directors that accompanies official NBER publications.

(C) 2021 by Larry Cordell, Michael R. Roberts, and Michael Schwert. All rights reserved. Short sections of text, not to exceed two paragraphs, may be quoted without explicit permission provided that full credit, including ( $)$ notice, is given to the source. 
CLO Performance

Larry Cordell, Michael R. Roberts, and Michael Schwert

NBER Working Paper No. 29410

October 2021

JEL No. G12,G14,G23,G24

\section{ABSTRACT}

We study the performance of collateralized loan obligations (CLOs) to understand the market imperfections giving rise to these vehicles and their corresponding economic costs. CLO equity tranches earn positive abnormal returns from the risk-adjusted price differential between leveraged loans and CLO debt tranches. Debt tranches offer higher returns than similarly rated corporate bonds, making them attractive to banks and insurers that face risk-based capital requirements. Temporal variation in equity performance highlights the resilience of CLOs to market volatility due to their closed-end structure, long-term funding, and embedded options to reinvest principal proceeds.

Larry Cordell

Federal Reserve Bank of Philadelphia

10 Independence Mall

Philadelphia, PA 19106

larry.cordell@phil.frb.org

Michael R. Roberts

The Wharton School

University of Pennsylvania

3620 Locust Walk, \#2319

Philadelphia, PA 19104

and NBER

mrrobert@wharton.upenn.edu
Michael Schwert

Assistant Professor of Finance

The Wharton School

3620 Locust Walk-SHDH 2451

University of Pennsylvania

Philadelphia, PA 19104

schwert@wharton.upenn.edu

A data appendix is available at http://www.nber.org/data-appendix/w29410 
Collateralized loan obligations (CLOs) have received a great deal of attention in recent years because of their rapid growth and broad reach. Standard \& Poor's (2020b) reports that two-thirds, or $\$ 2.1$ trillion, of leveraged loan issuance since the 2008 financial crisis has been funded by CLOs. A broad array of financial institutions invest in CLOs, including banks, insurers, pension funds, mutual funds, and hedge funds. As a result, U.S. and European regulators have expressed concerns about the growth of the CLO market and the financial system's exposure to these vehicles (MarketWatch (2019), Standard \& Poor's (2020a)).

In this paper, we address two questions arising from the growth of CLOs. What market imperfections are CLOs designed to address, and how large are the economic costs of these imperfections? With perfect capital markets, there is no role for CLOs, or securitization more broadly, because economic agents can costlessly transform cash flows. Thus, CLOs exist because of market imperfections. We test the implications of different imperfections for the performance of CLO assets and liabilities. In doing so, we provide the first largesample evidence on CLO performance, shedding light on the risks and rewards of these vehicles.

We begin by constructing a novel data set that offers a near-comprehensive view of the CLO market. The data include the full history of cash distributions to every CLO tranche, as well as information on contract terms, collateral holdings, and trading activity. The sample period, August 1997 to March 2021, encompasses three distinct business cycles including the financial crisis and the first year of the Covid-19 pandemic.

Our central finding is that CLO equity tranches provide statistically and economically significant abnormal returns, or "alpha," against a variety of public benchmarks. Using the generalized public market equivalent (GPME) framework of Korteweg and Nagel (2016), we find that the average completed CLO equity investment offers a net present value (NPV) of 66 cents per dollar invested, net of fees. This estimate equates to approximately $\$ 33$ million, or $6.6 \%$ of total assets, for the typical deal. The exact magnitude of the NPV estimate depends on the stochastic discount factor (SDF) specification, but all of the estimates are economically 
large and statistically significant. Before-fee GPME estimates imply that managers capture approximately $40 \%$ of the before-fee surplus. Because many managers fund a portion of the equity tranche in the CLOs they manage, this fraction is a conservative estimate of the total compensation of CLO managers.

Since equity investors receive the residual cash flow from the collateral pool after debt tranches are paid, these abnormal returns must be due to risk-adjusted price differentials between the leveraged loans in the collateral pool and the debt tranches issued to finance the vehicle. We confirm this relation by applying the GPME framework to the cash flows produced by CLO collateral and debt tranches. Although the conclusions regarding abnormal performance depend on the choice of SDF, debt tranches offer lower risk-adjusted returns than loan collateral in every specification.

Closer inspection reveals that the abnormal equity returns are concentrated among CLOs originated before 2010, so-called "CLO 1.0" transactions, and in particular by CLOs issued just before the onset of the financial crisis. CLOs issued in 2006 and 2007 locked in low-cost financing prior to the crisis and reinvested in high-yielding loans during and after the crisis. The result was a windfall of excess interest and principal for CLO equity investors as the economy recovered. CLOs have also proven resilient to the Covid-19 crisis, which has thus far had a negligible effect on equity distributions.

This resilience is attributable to several structural features of CLOs. First, CLOs are closed-end vehicles in which capital inflows and outflows are limited. Second, coverage tests are based on par values and credit ratings instead of market prices. Consequently, market volatility does not cause the diversion of cash flows to pay down debt tranches unless the volatility coincides with rating downgrades and defaults. Third, embedded options to reinvest collateral and reissue debt after a non-call period enable opportunistic trading and refinancing by CLO managers. Finally, CLOs employ a long-term funding structure known as "term leverage" that insulates the vehicle from rollover risk. Unlike most levered investment vehicles that use short-term debt (e.g., hedge funds), CLOs issue long-term debt 
with maturities in excess of seven years and fixed credit spreads.

We investigate several potential economic mechanisms behind the performance results. We find that the pool of leveraged loans comprising CLO assets generates gross returns that are economically indistinguishable from a broad-based index of leveraged loans. Net of fee returns are similar to those generated by a diversified portfolio of loan mutual funds. Thus, the average CLO manager does not exhibit skill in selecting leveraged loans relative to other market participants, though some managers do produce persistent outperformance relative to their peers.

Informational frictions that form the basis of traditional securitization theories (e.g., Glaeser and Kallal (1997), Riddiough (1997), DeMarzo and Duffie (1999), DeMarzo (2005)) are also unlikely responsible for our findings. The vast majority of CLOs are "open-market" transactions in which collateral is acquired through participation in broadly syndicated loans arranged by banks. This setting leaves relatively little scope for adverse selection, a conjecture confirmed by Benmelech, Dlugosz, and Ivashina (2012), who show that securitized loans perform no differently than nonsecuritized loans. ${ }^{1}$ Moral hazard has little role in explaining our results, as CLO managers do not expropriate value from debt investors by trading into riskier credits after issuance. Thus, the typical CLO does not appear to capitalize on imperfect information about the quality of loans in the collateral pool.

What CLOs do appear to capitalize on are the incentives of regulated financial intermediaries. Like CLO equity, debt tranches offer higher returns than public benchmarks. Discounting CLO debt cash flows using the returns of rating- and duration-matched corporate bonds, we find public market equivalent (Kaplan and Schoar (2005)), or PME, estimates for debt tranches that are statistically and economically significantly larger than one. These estimates imply annualized return premia ranging from $0.5 \%$ for AAA-rated tranches to

\footnotetext{
${ }^{1}$ We do find that the subset of middle-market CLOs, for which the collateral comprises loans arranged by the CLO manager, earn higher risk-adjusted returns on collateral and equity tranches than broadly syndicated loan CLOs. Though this difference is statistically insignificant due to the small number of middle-market deals, it suggests a role for CLOs in mitigating the costs of adverse selection where information asymmetry is most pronounced.
} 
$2.3 \%$ for B-rated tranches. We also show that AAA-rated CLO tranches earn high returns relative to other classes of AAA-rated asset-backed securities (ABS).

Unlike CLO equity, debt tranches do not offer abnormal risk-adjusted performance. None of the GPME estimates are significantly different from zero and most are negative. The gap between the PME and GPME estimates reflects priced risks related to economic differences between CLO debt and corporate bonds. CLO debt tranches are less liquid, are more likely to be prepaid, and have higher systematic risk exposure than corporate bonds (Coval, Jurek, and Stafford (2009), Elkamhi, Li, and Nozawa (2020)). Thus, while CLO debt tranches offer high yields relative to corporate bonds with the same rating and duration, they earn no additional return after adjusting for systematic risk.

The majority of funding for CLOs comes from AAA and AA-rated senior tranches, which are primarily held by capital-regulated entities: banks and insurance companies (DeMarco, Liu, and Schmidt-Eisenlohr (2020), Foley-Fisher, Heinrich, and Verani (2020)). Risk-based capital requirements create a preference for highly-rated assets when external equity financing is costly. Investing in senior CLO tranches instead of non-investment-grade loans relaxes balance sheet constraints and can expand the supply of credit to firms (Ivashina and Sun (2011), Shivdasani and Wang (2011), Nadauld and Weisbach (2012)). Indeed, Irani et al. (2020) show that bank capitalization plays an important role in the retention of risky syndicated loans that face high capital charges. The high yields on CLO tranches relative to similarly rated debt also cater to reach-for-yield incentives induced by ratings-based capital requirements (Brennan, Hein, and Poon (2009), Becker and Ivashina (2015), Merrill, Nadauld, and Strahan (2019)). ${ }^{2}$

Taken together, our results suggest that equity investors earn economic rents for providing risk-bearing capital that supports lending to risky borrowers and the issuance of highly-rated

\footnotetext{
${ }^{2}$ Regulatory arbitrage by banks and insurers has the potential to undermine financial stability by weakening capital buffers (Acharya and Richardson (2009)). While an examination of this issue is beyond the scope of this study, our results on CLO equity performance highlight an underappreciated benefit of this equilibrium. CLOs' long-term financing insulates them from rollover risk, which makes them better suited than banks, which are susceptible to runs, to hold risky loans during tumultuous periods.
} 
tranches. These rents are derived from either borrowers willing to pay high risk-adjusted spreads for loans due to an inadequate supply of intermediated credit (Schwert (2020)), intermediaries willing to earn low risk-adjusted spreads on CLO tranches to satisfy their demand for safe assets that reduce capital charges, or both.

Existing research on CLOs has focused on their implications for financial contracting (Shivdasani and Wang (2011)); lender behavior (Benmelech, Dlugosz, and Ivashina (2012), Wang and Xia (2014), Bord and Santos (2015), Peristiani and Santos (2019)); and fire-sale risk in the loan market (Elkamhi and Nozawa (2020), Kundu (2021)). We extend this body of work by identifying the market frictions behind the issuance of CLOs and measuring the corresponding costs. In the process, we provide the first large-sample empirical evidence on the risk-adjusted investment performance of CLO assets and liabilities.

Our risk-adjusted performance evidence builds on prior research examining the pricing of collateralized debt obligations (CDOs). Most papers in this literature focus on tranches of broad credit default swap indices (CDX) due to data availability. ${ }^{3}$ CLOs differ from CDX in their function, channeling capital to firms rather than solely providing a venue for hedging and speculation by investors, as well as their form, including coverage tests to bolster senior tranches and incentives for managerial performance. Further, the empirical evidence on CDX pricing is mixed. Coval, Jurek, and Stafford (2009) use a structural model based on Merton (1974) to show that senior tranches are overpriced and equity tranches are underpriced. Collin-Dufresne, Goldstein, and Yang (2012) and Seo and Wachter (2018) argue that CDX debt tranches are fairly priced when a more appropriate model is used. Longstaff and Myers (2014) examine the returns of CDX equity tranches and find that they earn no significant alpha. Thus, our data and findings provide new insights into the performance of a large and

\footnotetext{
${ }^{3}$ Exceptions include Ospina and Uhlig (2018) and Cordell, Feldberg, and Sass (2019), who investigate the performance of residential mortgage-backed securities and CDOs that invested in asset-backed securities (ABS CDOs), respectively, during the financial crisis. Erel, Nadauld, and Stulz (2014) examine bank performance in the financial crisis as a function of AAA-rated securitization tranche holdings. Chernenko (2017) studies the incentives and performance of CDO managers. In a similar spirit to this paper, An, Deng, and Gabriel (2011) examine pricing distortions driven by asymmetric information in the commercial mortgage-backed securities (CMBS) market.
} 
growing segment of the structured finance space.

Our results also relate to work on managerial skill and ratings inflation in structured finance markets. Liebscher and Mahlmann (2017) and Fabozzi et al. (2021) argue that active trading by CLO managers reveals differential skill. We too find significant cross-sectional heterogeneity in manager style and performance. However, in aggregate, CLO managers do not exhibit superior skill in selecting or trading collateral relative to other participants in the leveraged loan market. Griffin and Nickerson (2020) argue that CLO tranches are significantly riskier than their credit ratings suggest during the Covid-19 crisis. We show that over the history of the CLO market, debt tranches experience significantly lower default rates than similarly rated corporate bonds. This evidence implies that any mistakes in rating CLOs are as yet unrealized, despite two significant economic crises in our sample period.

The remainder of the paper is organized as follows. Section 1 discusses our data sources and sample construction. Section 2 describes the institutional details surrounding CLOs and the conceptual framework that guides our empirical analysis. Section 3 describes the mechanisms governing payments to investors. Section 4 examines the performance of CLO equity tranches. Section 5 explores possible economic mechanisms behind CLO equity performance. Section 6 concludes.

\section{Data}

\subsection{CLO Information}

We use CLO data from Intex Solutions, a leading provider of information on structured finance products. Intex obtains data directly from trustees, third-party financial institutions responsible for enforcing the indenture that governs the structure, and packages it for use by both buy- and sell-side market participants. The data include information on deal structures, the histories of collateral holdings and transactions, cash distributions to each tranche, and fee payments. Our sample period begins in August 1997 and ends in March 2021. 
Figure 1 compares the coverage of the Intex CLO data to the total size of the U.S. CLO market as reported by the Securities Industry and Financial Markets Association (SIFMA) and JPMorgan Chase. Since 2007, Intex's coverage has exceeded 90\% of the entire CLO market, with near-complete coverage since the financial crisis. This difference is due to the inclusion of a small number of "balance-sheet" CLOs issued by investment banks, collateralized bond obligations (CBOs), and more recently, commercial real estate CLOs in the aggregate market data. We exclude these vehicles from our analysis to maintain focus on a homogeneous set of deals. We also exclude resecurizations, which differ from standard CLOs because their collateral consists of CLO tranches instead of corporate loans. Thus, our data offer near-comprehensive coverage of the universe of standard CLOs. ${ }^{4}$

Table 1 summarizes the Intex data by annual vintage. CLO issuance grew rapidly in the early 2000s before the financial crisis all but eliminated new deals. Beginning in 2011, issuance increased rapidly again, with aggregate dollar issuance in 2014 exceeding the precrisis peak. The delineation created by the financial crisis has led market participants to denote CLOs originated before and after the financial crisis as CLO 1.0 and CLO 2.0, respectively. More precisely, for the purpose of this study, CLO 1.0 consists of deals issued before 2010 and CLO 2.0 consists of deals issued in 2010 and after. More than just a temporal distinction, CLOs originated before and after the crisis differ in important ways that we highlight below.

The typical deal size is around $\$ 500$ million with a leverage (debt-to-value) ratio of approximately $90 \%$. Outside of a small number of deals issued during the financial crisis, there is a remarkable degree of uniformity across deals in terms of size and leverage, consistent with the findings in Benmelech and Dlugosz (2009). Further detail on the distributions of these variables may be found in the Internet Appendix.

\footnotetext{
${ }^{4}$ Figure 1 contains a few years in which the outstanding amount in Intex exceeds the aggregate market size reported by SIFMA and JPMorgan Chase. These small differences are due to the timing of issuances and repayments.
} 


\subsection{Sample Selection}

For our analysis, we require the identity of the collateral manager, information on distributions to each tranche, the presence of an equity tranche in each deal, leverage of at least $50 \%$, and U.S. dollar denominated tranches. We focus on CLOs that invest in institutional term loans, as opposed to lines of credit. These requirements reduce our sample size from 2,265 to 2,216 deals.

An additional requirement is a complete history of payments to each tranche, which reduces the sample to the 2,131 deals reported in the bottom row of Table 1. Missing data on distributions arise for two reasons. The first reason is the growth of Intex as a data provider over the last two decades. Older CLOs are less populated than more recent deals. The second reason is the relaxation of reporting requirements for CLO trustees after all debt tranches have been repaid. This relaxation can result in missing liquidation payments to equity tranches, a small number of which we fill with the aid of Bloomberg data and trustee reports. See the Internet Appendix for further details on the imputation of missing cash flows and our sample selection procedure.

A potential concern with this data requirement is selection bias if reporting is correlated with performance. However, our sample is only modestly affected by this requirement, with most of the $5.9 \%$ reduction in observations coming from the CLO 1.0 period. The sample contains $82 \%$ of deals issued before 2010 and $98 \%$ of deals issued since 2010 . Further, consistent with our sample's representativeness, we find CLO tranche default rates that are similar to those reported by Standard \& Poor's (2014) for rated CLOs issued between 1994 and $2013 .{ }^{5}$ Ultimately, our sample offers the most comprehensive coverage of the CLO universe available in the academic literature and includes more than twice as many deals as prior papers studying the performance of CLOs (e.g., Liebscher and Mahlmann (2017),

\footnotetext{
${ }^{5}$ Standard \& Poor's (2014) reports that default rates among publicly rated U.S. CLO tranches issued from 1994 to 2013 were $0.15 \%$ for investment-grade tranches and $1.05 \%$ for non-investment-grade tranches. The default rates in our sample are $0.23 \%$ for investment-grade tranches and $1.48 \%$ for non-investment-grade tranches issued over the same period. As of March 2021, neither Moody's nor Standard \& Poor's have noted any defaults from the CLO 2.0 vintages.
} 
Fabozzi et al. (2021)).

The last column of Table 1 reports the number of deals that were fully paid down (i.e., completed) by March 2021. CLOs have a typical maturity of eight years, so the number of completed deals mechanically declines as we approach the end of the sample horizon. However, we observe several completed deals towards the end of our sample for which the realized lifespan is well below eight years. These shortened deals are a result of liquidations in which all of the liabilities are prepaid and the special purpose vehicle terminated. Liquidations are distinct from refinancings and resets, two additional embedded options available to CLO equity investors. In a refinancing, some or all of the deal's existing liabilities are called and reissued at prevailing market spreads to lower the cost of capital, while other aspects of the deal are unchanged. In a reset, the liabilities are refinanced and other terms of the CLO indenture are modified, typically for the purpose of extending the reinvestment period and deal maturity. Because this optionality is a source of value for equity investors and a risk for debt investors, we track each deal from origination through any of these events in our analysis of tranche performance.

\subsection{Management Fees}

Intex provides a complete history of management fee payments for $69 \%$ of the completed deals in our sample. For deals without historical fee data, we estimate fees using the contractual fee rates specified in the offering memorandum, available for an additional $3 \%$ of completed deals. Specifically, we calculate the senior fee as a percentage of the collateral balance each quarter, as well as a subordinated fee that is paid conditional on a non-zero distribution to equity. Incentive fees are often structured in a complex manner, so we omit them from the estimation to avoid overstating the before-fee cash flows. Finally, we use the sample median senior and subordinated fees of 15 and 30 basis points (bps), respectively, for the remaining $28 \%$ of deals with neither historical nor contractual fee data.

Figure 2 shows that the typical fee is about 50 bps of the collateral balance before the 
incentive fees are triggered. The dip in payments after the financial crisis is due to the failure of coverage tests, which we describe shortly. The increase in fee payments near the maturity of the CLO 1.0 vintages demonstrates the impact of incentive compensation on successful deals. Finally, we note a slight reduction in fees over the last few years. ${ }^{6}$

\subsection{Supplementary Data}

We supplement the Intex CLO information with data from several other sources, which are detailed in the Internet Appendix. IHS Markit provides information on loans in the collateral pool since 2002. Specifically, the Markit data contain loan characteristics and price quotes sourced from dealers in the over-the-counter secondary market for leveraged loans. These quotes are used by loan mutual funds to mark their portfolios to market.

Loan mutual fund data for 312 funds come from Morningstar Direct. These data are merged with return information from the Center for Research in Security Prices (CRSP), resulting in a final sample of 290 loan mutual funds for which we have return information. The S\&P/LSTA U.S. Leveraged Loan 100 Index total return is sourced from Bloomberg.

To construct our benchmark indices for CLO debt tranches, we use daily bond-level quote data from Bank of America Merrill Lynch and interest rate swap data from Bloomberg. Finally, we obtain equity and bond index returns from Bloomberg and factor returns from Ken French and Zhiguo He's websites.

\section{Institutional Details and Conceptual Framework}

A CLO is a special-purpose entity that issues a prioritized set of securities - tranches - to investors and uses the proceeds to acquire and manage a portfolio of corporate loans. There are two types of CLOs that differ by the type of loans they acquire: broadly syndicated

\footnotetext{
${ }^{6}$ One limitation of our fee data is that we cannot observe side agreements between investors and managers. According to several CLO managers with whom we spoke, "back-end rebates" and other transfers between managers and investors occur outside of the indenture and are not made available to the CLO trustee.
} 
loan (BSL) and middle-market (MM) transactions. Broadly syndicated loan CLOs invest in loans to large firms (i.e., EBITDA in excess of $\$ 100$ million) that are originated by banks and syndicated widely to bank and nonbank investors. The Intex data contain 2,085 BSL CLOs with total par value of $\$ 1.09$ trillion, accounting for the bulk of our sample. In middlemarket deals the CLO manager plays a dual role, originating loans to small- and medium-size companies, often in cooperation with a small "club" of related lenders, and then including the loans in the CLO collateral pool they manage. In aggregate, there are $180 \mathrm{MM}$ CLOs worth $\$ 87$ billion in the Intex data. We pool these deal types in most of our analysis, noting when we observe differences, because the findings in each market segment are qualitatively similar.

\subsection{CLO Balance Sheet and Conceptual Framework}

We organize our analysis of CLOs around their balance sheets. The assets, or collateral, consist primarily of floating-rate, senior secured term loans with maturities between five and seven years. The typical CLO holds loans issued by 150 to 250 distinct borrowers. Standard contract terms limit exposure to any industry at $15 \%$ of the loan pool and to any company at $2 \%$ of the loan pool. Contracts also limit the portfolio share of loans paying fixed or semi-annual (as opposed to quarterly) coupons, loans rated CCC + or below, and loans that mature after CLO debt securities.

The liabilities consist of a combination of debt and equity tranches. Debt tranches are floating-rate claims secured by the loans in the collateral pool. The floating-rate nature of these claims matches that of the collateral, thereby insulating investors from interest rate risk. Debt tranches are differentiated by their priority in the CLO capital structure - senior (AAA and $\mathrm{AA})$, mezzanine (A and $\mathrm{BBB})$, and junior (BB and $\mathrm{B}$ ) - and consequently the interest rate spread they are promised. Equity investors receive unsecured, unrated claims.

The CLO balance sheet is visualized in Figure 3. Panels A and B present the valueweighted average balance sheets for the CLO 1.0 and 2.0 eras, respectively. Several features 
and differences across eras stand out. First, CLO assets are comprised entirely of noninvestment-grade, or high-yield, loans. Second, the composition of assets in the CLO 2.0 period has shifted towards lower-rated, and therefore riskier, collateral. The median loan rating for CLO 1.0 assets is $\mathrm{B}+$; for CLO 2.0 assets the median rating is B.

Comparing the liability structures, we see that the leverage ratio of a typical CLO fell, albeit modestly, from $91 \%$ in CLO 1.0 to $89 \%$ in CLO 2.0. More noticeably, the AAA-rated portion of the capital structure decreased from $72 \%$ in CLO 1.0 to $61 \%$ in CLO 2.0. Put differently, subordination increased in CLOs after the financial crisis in an effort to further insulate highly-rated debt tranches from potential losses. This change was due in large part to changes in rating agency criteria that included increases in default probability assumptions by a factor of 30\% (Moody's (2010)) and a tripling of default correlation assumptions (Nickerson and Griffin (2017)) in response to the severe losses of ABS CDO - not CLO - tranches in the financial crisis.

Investors vary across the priority structure of claims based on their preferences and regulatory constraints. Banks invest primarily in AAA-rated senior tranches. Insurance companies and pension funds invest across the capital structure, while hedge funds and other alternative asset managers concentrate in mezzanine and junior debt. The equity tranche is usually funded in part by a private credit fund raised by the CLO manager's parent company, with outside investors contributing as well.

In addition to illustrating the CLO structure and how it has evolved, Figure 3 motivates the conceptual framework used in our empirical analysis. Under the perfect capital markets assumptions of Modigliani and Miller (1958), there is a unique stochastic discount factor that prices all cash flows. Under this null hypothesis, the balance sheet identity is:

$$
\frac{E_{t}\left[m_{t+1}\left(P_{t+1}^{c}+x_{t+1}^{c}\right)\right]}{P_{t}^{c}}=\frac{P_{t}^{d}}{P_{t}^{c}} \frac{E_{t}\left[m_{t+1}\left(P_{t+1}^{d}+x_{t+1}^{d}\right)\right]}{P_{t}^{d}}+\frac{P_{t}^{e}}{P_{t}^{c}} \frac{E_{t}\left[m_{t+1}\left(P_{t+1}^{e}+x_{t+1}^{e}\right]\right.}{P_{t}^{e}}
$$

where $P_{t}^{i}$ is the price at time $t$ of claim $i$, for $i$ equal to collateral $(c)$, debt $(d)$, or equity $(e)$. 
The stochastic discount factor is denoted by $m$ and the payoff of claim $i$ in period $t+1$ is denoted by $x_{t+1}^{i}$. The expectations, $E_{t}$, are conditional on the time $t$ information set. Under the null hypothesis of perfect capital markets, all three ratios of expected value to price are equal to one. Put differently, the price of each claim is equal to the sum of the discounted future expected cash flows.

\subsection{CLO Life Cycle}

The life cycle of a typical CLO begins with the CLO manager securing a bank line of credit, called a warehouse facility, to purchase the loans that will comprise the collateral pool. The warehousing process of acquiring loans with the proceeds of the credit line takes six to nine months, after which the CLO is marketed to investors to raise long-term financing.

CLO managers pay down the line of credit with the issuance proceeds and continue purchasing loans from the market. This ramp-up period spans several months, typically no more than six, until the collateral pool reaches the target principal amount specified in the CLO indenture. At this point, the CLO becomes effective, and the manager shifts roles from building to managing the loan portfolio. The distribution of interest and principal payments received from the collateral pool begins at quarterly intervals. Covenants, such as coverage tests, become effective. ${ }^{7}$

Once effective, the CLO enters two overlapping but distinct phases. The first is the non-call period, which lasts two years. During this period, investors are protected from resets, refinancings, and early liquidation. The second is the reinvestment phase, which lasts four to five years. During this phase, the CLO manager actively trades loans to manage the credit risk and principal balance of the collateral pool, subject to the collateral quality requirements and coverage tests spelled out in the CLO indenture.

The amortization period is the last phase and occurs after the reinvestment phase ends.

\footnotetext{
${ }^{7}$ Coverage tests ensure that the collateral is sufficient to repay secured noteholders. Three common tests include overcollateralization, interest coverage, and interest diversion. See Standard \& Poor's (2018) for more details.
} 
All principal generated by the collateral pool is used to retire the outstanding CLO tranches and unwind the structure. At this stage, the manager's ability to buy and sell collateral is limited to the reinvestment of unscheduled principal payments. Thus, CLOs are actively managed investment vehicles for much of their lives.

\section{Distributions to CLO Investors}

\subsection{Distributions to Debt Tranches}

Cash flows from the collateral pool are distributed to investors according to a "waterfall," or priority structure, set forth in the CLO indenture. Interest received from the collateral pool is first used to pay administrative expenses and senior management fees. The remainder is used to pay interest on the secured notes beginning with the senior tranches, followed by the mezzanine tranches, and then the junior tranches. The priority of subordinated management fees varies from deal to deal, but the typical structure involves a fixed fee before equity is paid and an incentive fee conditional on the cumulative equity internal rate of return (IRR) exceeding a prespecified threshold. Principal payments received during the reinvestment period are used to invest in new loans. After the reinvestment period, during the amortization phase, principal payments follow a waterfall similar to that used for interest payments.

An exception to this distribution scheme occurs when a coverage test is failed. Failure occurs when the quality of the collateral pool deteriorates because of defaults or a large fraction of downgrades to $\mathrm{CCC}+$ or lower. The consequence of failure is the repurposing of loan interest payments to pay down the principal of senior noteholders until the coverage test is passed. Any remaining interest is then used to pay interest according to the priority structure. Thus, coverage tests act as automatic stabilizers that deleverage the capital structure of the CLO and protect senior investors against the loss of principal in the event of credit deterioration. 


\subsection{Distributions to Equity Tranches}

Distributions to equity come from excess interest and principal payments generated by the collateral pool. This excess cash flow arises from two credit enhancements present in all CLOs: overcollateralization and excess spread.

Overcollateralization refers to the aggregate par amount of the collateral pool being greater than that of the debt tranches. This excess collateral is purchased with the proceeds from the equity investors, though they have no contractual claim to it (i.e., equity is unsecured). As with interest payments, this excess collateral can be distributed to equity investors only after all of the debt tranches have been made whole. The average CLO has $\$ 1.12$ of collateral for each dollar of debt issued. Because leverage and overcollateralization are inversely related, Table 1 shows that overcollateralization has been increasing over time.

Excess spread refers to the difference in the value-weighted average interest spread on the collateral and that of the CLO debt. As long as the loans in the collateral pool perform by making interest payments, they produce cash flows that are greater than the required interest payments to debtholders. The excess is distributed to equityholders.

Panels A and B of Figure 4 illustrate the excess spread in our sample. Panel A presents the principal value-weighted average coupon rate of loans in the collateral pool. Panel B presents the same for CLO debt tranches. We compute these coupon rates by summing the interest rate spread and base rate, typically three-month LIBOR. We also account for the presence of some fixed-rate CLO debt tranches and interest rate floors in the loan contracts. These are promised rather than realized coupon rates - the excess cash flow to equityholders also depends on the extent of collateral defaults and coverage test failures.

We note three aspects of these plots. First, the time-series pattern in both figures is similar, reflecting the evolution of LIBOR and credit risk premia over the sample period. Second, the level of the collateral coupon rate is higher than that of the CLO tranche coupon rate at each point in time, reflecting the excess spread. Third, the coupon rates differ across vintages at the same point in time, with particularly striking differences between the debt 
tranche coupon rates of pre- and post-crisis vintages.

Panels $\mathrm{C}$ and D in Figure 4 present the after-fee distributions to CLO equity tranches. In addition to reporting the time-series median by vintage group (Panel $\mathrm{C}$ ), we also report the median in event time relative to each CLO's closing date (Panel D) to ease comparisons across vintage groups. Payout yields to equity investors are sensitive to changes in the macroeconomic environment. We see a V-shaped fall and rise in equity payout yields around the financial crisis, when equity distributions fell to zero for the majority of CLOs. The steep fall in distributions was driven by the failure of coverage tests due to loan defaults and rating downgrades, which resulted in the diversion of cash flows to pay down senior tranche principal. $^{8}$

Focusing on the CLO 2.0 vintages, we notice a steadily declining life cycle of payout yields. This pattern results from the accumulation of defaults over a deal's life, which gradually reduce the principal value of the collateral pool and the interest stream it generates. Although the post-crisis period is not known for having a high level of corporate defaults, Moody's (2018) reports that global loan defaults by rated firms amounted to $\$ 155.2$ billion from 2011 to 2017, equivalent to approximately $10 \%$ of the leveraged loan market. Most of these defaults were by the non-investment-grade firms that populate the collateral pools of CLOs. Given the high leverage of the typical CLO, this level of default is sufficient to significantly reduce the excess cash flow available for CLO equityholders.

Comparing the pre- and post-financial crisis eras, CLOs issued immediately after the crisis have initial payout yields that are similar to the initial level observed in pre-crisis deals. However, at the same point in time after the financial crisis, the pre-crisis CLO vintages have noticeably higher payout yields than the newly issued post-crisis deals. This difference stems from the long-term liability structure of the CLO and the manager's ability to reinvest in the collateral pool.

\footnotetext{
${ }^{8}$ Anecdotal evidence suggests there were also some deals (e.g., Race Point IV) with automatic triggers to reinvest excess cash flow in additional collateral instead of making payments to equity investors during periods of market stress. Our data do not contain this level of contractual detail, but we observe that most observations in the financial crisis with no equity payout coincide with senior tranche principal payments.
} 
Pre-crisis CLOs issued debt and purchased loans at relatively low spreads. When the crisis hit in 2008, leveraged loan spreads increased, as did the spreads promised to debt investors in newly issued CLOs. As the economy recovered, spreads remained at relatively high levels in the persistently low interest rate environment (Roberts and Schwert (2020)). These high spreads entered the CLO collateral pools as loans turned over because of maturities, prepayments, amendments, and defaults. Thus, as spreads in the collateral pool increased, spreads on the liability side remained fixed at low, pre-crisis levels due to the long-term nature of CLO debt financing. The net effect is that pre-crisis CLOs earned higher excess spreads after the crisis, despite losing some collateral value to defaults during the Great Recession.

\section{Equity Performance}

This section presents our findings on the performance of CLO equity tranches. We begin by providing evidence on several standard performance metrics used by practitioners and in earlier academic research. The advantage of these metrics is that they can be computed at the deal level. The disadvantage is that they do not adequately adjust for risk. Next, we present estimates of the risk-adjusted performance of CLO equity using the GPME framework from Korteweg and Nagel (2016). We then focus attention on the performance of CLOs during the two economic crises in our sample period, highlighting the features of CLOs that make their performance resilient to market fluctuations. Finally, we quantify the role of embedded options to reinvest collateral proceeds and refinance liabilities in determining equity performance. 


\subsection{Descriptive Performance Results}

Table 2 presents estimates of the after-fee performance of CLO equity tranches by annual vintage, the CLO 1.0 and 2.0 eras, and the full sample period. ${ }^{9}$ Panel A reports internal rates of return (IRRs), computed as the discount rate equating the present value of the cash distributions to the value of the original investment. The average IRR was $9.9 \%$ for CLOs issued between 1997 and 2016. As a point of reference, Harris, Jenkinson, and Kaplan (2014) find an average IRR of $10.1 \%$ for private equity buyout funds raised between 2000 and 2008 , which is lower than the average IRR of $13.1 \%$ for CLOs issued during the same period.

Equity IRRs exhibit significant variation in the cross-section and time series. CLOs issued between 2005 and 2007, just before the financial crisis, exhibit especially robust performance. Median IRRs for these three years are all above 13\%, despite an average lifetime that encompasses the Great Recession. Panels C and D of Figure 4 hint at these results. Recall that CLO managers of these pre-crisis vintages were able to reinvest principal payments during the crisis to take advantage of (1) discounted loans in the secondary market and (2) increasing interest rate spreads on newly issued loans. Because CLO funding spreads were fixed at low, pre-crisis levels, equity investors benefited from even more excess interest as a result of (2). Further, the additional overcollateralization resulting from (1) led to larger liquidating payments to equityholders. ${ }^{10}$

Also noticeable is the low average IRR for CLO 2.0 deals relative to that for CLO 1.0 deals $-4.9 \%$ versus $13.0 \%$. However, this difference is likely exaggerated because of rightcensoring among the most recent vintages. Completed deals from the 2014 to 2016 vintages are comprised primarily of early liquidations, which are predicated on lackluster prospects for the equity claim. Thus, the outstanding equity tranches from these vintages will likely

\footnotetext{
${ }^{9}$ The performance metrics computed are based on an initial investment equal to the par value of equity from trustee reports. To the extent that equity investors purchase their stakes at a discount to par, which conversations with market participants indicate is not unusual, then our analysis understates the true performance of CLO equity.

${ }^{10}$ Of course, these benefits are constrained by the potential for loan defaults or sales at discounted prices. The overall performance of CLO equity reflects the net effect of these opposing forces. We explore the contribution of collateral reinvestment to equity performance in Section 4.4.
} 
perform better than those that were liquidated early.

Panels B and C of Table 2 present public market equivalent (Kaplan and Schoar (2005)), or PME, estimates that reinforce these findings. For each CLO, we discount the cash flow stream using the realized returns of a benchmark portfolio and sum the present values. We then compute the ratio of this sum to the size of the initial investment. The result is a profitability index that measures the present value of distributions for each dollar invested. A PME greater than one indicates that investors earned more in present value terms than what they paid, while a PME less than one suggests the opposite.

We use two benchmarks for our calculations. The first is the S\&P 500 Index, which is a common performance benchmark for alternative asset managers who compare their performance to broad market indices (Kaplan and Schoar (2005)). In other words, the S\&P 500 Index is a practically relevant benchmark, though perhaps not a theoretically relevant benchmark in light of the implicit assumption that the beta of CLO equity is equal to one. We refer to the PME measured relative to the S\&P 500 Index as "PME Market."

The second benchmark is the S\&P 500 Banks sub-index, a portfolio of the largest bank stocks. As a type of shadow bank, CLOs are similar to commercial banks in several ways. Both have highly levered capital structures and assets comprised primarily of loans. Like banks, CLOs generate profits by borrowing at a market rate and lending to firms at a higher rate. Although they pursue different forms of financing, with banks relying on shortterm deposits and wholesale funding while CLOs issue long-term floating-rate notes, their financing costs are similarly exposed to short-term interest rates. Longstaff and Myers (2014) find that the equity tranche returns of investment-grade and high-yield CDX, widely traded synthetic CDOs of the most liquid corporate credit default swaps, behave similarly to the returns of financial stocks. Of course, there are also important differences, such as banks' activities other than commercial lending and the influence of deposit insurance. We refer to the PME measured relative to the S\&P 500 Banks sub-index as "PME Bank."

Panel B reports an average PME Market of 1.33, implying that CLO equity earned higher 
returns than an index of public equities. Once again this compares favorably against the PMEs of buyout funds, which Harris, Jenkinson, and Kaplan (2014) estimate as 1.27 for vintages from 2000 to 2008. Looking across vintages reveals that this outperformance comes largely from the pre-crisis vintages, 2005 to 2007, much like what we saw in Panel A. We also note a decrease in the dispersion of PMEs in the CLO 2.0 era, as evidenced by their shrinking standard deviation and interquartile range.

Panel C presents results for the PME Bank metric. The relatively poor performance of banks during and after the financial crisis leads to PMEs that are substantially larger when compared to their counterparts in Panel B. The overall average PME of 2.38 is impressive, but as with prior panels, there are significant differences between CLOs issued before and after the financial crisis. Buying CLO equity prior to 2009 earned investors 3.44 times what they would have earned investing in bank equities. The analogous multiplier is only 0.80 for vintages from 2009 onward, implying that bank stocks have offered higher returns than CLO equity since the financial crisis.

CLO managers often retain equity to provide a signal of quality to investors or, for a brief time during our sample, to comply with regulations. ${ }^{11}$ To evaluate the performance of "inside" equity held by CLO managers, we add the management fees described in Section 1.3 to the after-fee equity distributions to form a panel of before-fee equity payouts.

Table 3 shows, unsurprisingly, that all of the equity performance metrics are higher when management fees are included. What is striking are the magnitudes of the increases. CLO managers earn substantial fees. With the typical CLO having a leverage ratio of 90\%, senior and subordinated management fees totaling $0.5 \%$ of the collateral balance are equivalent to approximately $5 \%$ of the equity balance per year. This fee stream is even richer for the CLO

\footnotetext{
${ }^{11}$ Requirements of CLO managers to take positions in the CLOs that they manage have varied over time. Throughout our sample period, retention of equity is dictated by market participants' desire to invest in CLOs whose managers have skin in the game. In addition, the Credit Risk Retention Rule of the Dodd-Frank Act legally required CLO managers to take positions in their CLOs as of December 24, 2016. Specifically, managers were required to retain 5\% exposure to the CLO assets, through either a "horizontal" investment in equity or a "vertical" investment in each tranche. However, open-market CLO managers were exempted from this requirement by the D.C. Circuit court ruling in February 2018. See Loan Syndications 63 Trading $A s s^{\prime} n$ v. SEC, 223 F. Supp. 3d 37 (D.D.C. 2016).
} 
1.0 transactions that cleared the IRR threshold for incentive compensation.

As a result, the average IRR increases by more than $50 \%$ when fees are included, rising from $9.9 \%$ to $16.5 \%$. The PMEs increase by approximately $25 \%$. While the time-series patterns are similar to those found in Table 2, a notable difference is that the PMEs for CLO 2.0 deals are much closer to one.

The results in Tables 2 and 3 paint a consistent picture of CLO equity performance. First, CLO 1.0 deals earned higher returns than CLO 2.0 transactions, based on their internal rates of return and public market equivalents. Second, the symmetric performance distributions in Table 2 imply that the results are not driven by outliers. Third, CLOs issued just prior to the financial crisis performed particularly well.

\subsection{Risk-Adjusted Performance}

The IRR and PME analyses provide descriptive evidence on the performance of CLOs, but they cannot tell us whether CLO equity offers abnormal performance. IRRs make no attempt at risk adjustment and PMEs implicitly assume that the market beta of CLO equity is equal to one. To address this issue, we implement the generalized public market equivalent (GPME) of Korteweg and Nagel (2016). ${ }^{12}$ This framework adjusts for the systematic risk exposure of test assets and allows for statistical inference that accounts for correlation across deals. Specifically, the GPME specifies an exponentially affine stochastic discount factor $(\mathrm{SDF})$,

$$
m_{t+h}^{h}=\exp \left(a h-b_{1} r_{m, t+h}^{h}-b_{2} r_{x, t+h}^{h}\right)
$$

where $a, b_{1}$, and $b_{2}$ are parameters chosen to price the factor payoffs exactly, $r_{m, t+h}^{h}$ is the $h$-period excess return on the stock market, and $r_{x, t+h}^{h}$ is the $h$-period return on an additional factor meant to capture risks unique to CLO equity.

The GPME is the present value of cash flows discounted using this SDF, net of the

\footnotetext{
${ }^{12}$ We thank Arthur Korteweg and Stefan Nagel for providing the GPME code on their websites.
} 
amount invested. Cash flows are normalized to an initial investment of one dollar so the baseline GPME is relative to zero, in contrast to PMEs, which have a baseline of one. The expected value of the GPME is interpreted as the net present value (NPV) of a one dollar investment. The SDF parameters are chosen to correctly price the risk-free asset and factor returns, which ensures that the valuation properly benchmarks against contemporaneous factor performance. A limitation of this approach is its reliance on a sufficiently long time series, which limits its use to the entire sample.

Table 4 presents the GPME estimates for the three components of the CLO balance sheet - collateral, debt, and equity - under a common SDF. For robustness, we consider several SDF specifications, beginning with the capital asset pricing model (CAPM). To account for the option-like payoffs of CLO tranches and potential segmentation between the corporate equity and debt markets, we augment the equity market return with the returns on the S\&P/LSTA U.S. Leveraged Loan 100 Index, the Bloomberg-Barclays U.S. Corporate High Yield Bond Index, and the CBOE S\&P 500 Put-Write Index in separate two-factor models. We also consider the intermediary asset pricing model from He, Kelly, and Manela (2017), which has been shown to successfully price risky fixed-income assets including corporate bonds and credit default swaps.

The top portion of Table 4 reports after-fee GPME estimates. All of the specifications reveal a positive equity GPME that is statistically significant at the $1 \%$ level. The estimates imply that in present value terms, outside equity investors earn between 37 cents and 66 cents per dollar invested above what they could earn by investing in public market factors. ${ }^{13}$ The GPME estimates for collateral and debt are statistically noisy, due largely to the limited variation in these cash flow streams, but are consistent with the balance-sheet intuition discussed earlier. Recall that the balance sheet identity dictates that any abnormal returns

\footnotetext{
${ }^{13}$ It is possible that the outperformance of CLO equity reflects compensation for illiquidity. Although we cannot rule out this possibility, we should note that illiquidity does not necessarily imply a large effect on returns. Following Constantinides (1986), investors in equity tranches are likely to have a long horizon, while impatient investors stay away in anticipation of high secondary market transaction costs. In this equilibrium, the marginal equity investor would require little compensation for illiquidity. The Internet Appendix shows that the GPMEs are unaffected by including the Pastor and Stambaugh (2003) liquidity factor in the SDF.
} 
to equity must come from a risk-adjusted price differential between collateral and debt. The GPME is larger for collateral than for debt tranches in every specification, though the choice of SDF affects whether the GPME is positive or negative. The weighted averages of the collateral and debt tranche GPMEs, reported as "implied equity," are slightly lower but in line with the equity GPMEs.

The middle section reports analogous estimates for "inside" equity investments by CLO managers, inclusive of estimated fees. In line with the after-fee results, the equity GPMEs are positive and statistically significant in every specification. Economically, the point estimates imply that in present value terms, CLO managers earn between 69 cents and 111 cents per dollar invested above what they could earn by investing in public market factors. The difference between the after-fee and before-fee GPME estimates implies that the present value of manager compensation amounts to between 31 cents and 44 cents per dollar of equity raised, or between $40 \%$ and $45 \%$ of the surplus created by CLO issuance. Because managers often hold a portion of the equity tranche, these shares are likely conservative estimates of the surplus extracted by managers.

Together, these results imply that CLO equity earns "alpha" that is shared by outside equity investors and the CLO manager. Because equity investors receive the residual cash flow from the collateral pool after debt tranches are paid, this abnormal return comes from the difference between the risk-adjusted pricing of leveraged loans and CLO debt tranches. Specifically, CLO collateral is inexpensive, or earns high returns, relative to CLO debt. Unfortunately, the limited statistical power afforded by the CLO market's relatively short history prevents us from taking a strong stance on whether collateral or debt are mispriced.

\subsection{Resilience to Market Volatility}

To better understand CLO equity performance in periods of market stress, we examine the balance sheet condition and cash distributions of CLOs during the financial crisis of 2008 and the more recent Covid-19 crisis of 2020. Figure 5 presents several measures of 
interim performance for CLOs outstanding in the financial and Covid-19 crises. The left side of each panel is based on data from December 2007 to June 2010, while the right side covers March 2019 to March 2021. The scale of the $y$-axes in each row of plots is the same, allowing for direct comparisons across the two periods. The $x$-axes have the same scale within each column to ease comparisons across the different measures of CLOs' financial health. We emphasize that these measures represent only performance to date and should not be compared to previous measures of completed deal performance such as IRRs or PMEs.

Panel A of Figure 5 presents median market value coverage ratios for CLO debt tranches by rating category. These ratios are computed by dividing the market value of the collateral portfolio by the principal balance of a debt tranche and all tranches senior to it. To illustrate, consider a CLO with just two tranches: a AAA-rated tranche with principal of $\$ 100$, and a BBB-rated tranche with principal of $\$ 20$. If the market value of collateral is $\$ 140$, then the AAA coverage ratio is $1.4(140 / 100)$, and the BBB coverage ratio is $1.17(140 / 120)$. Ratios greater than one correspond to a full expected recovery, while values below one correspond to an expected loss of principal.

Several features of Panel A are worth noting. First, coverage ratios respond to fundamental shocks quickly, as indicated by the steep drops following the Lehman Brothers bankruptcy and the imposition of economic shutdowns to fight Covid-19. Second, nearly all debt tranches were undercollateralized during the financial crisis, with the median AAArated tranche exhibiting a coverage ratio of 0.91 at the end of 2008 . Finally, coverage ratios are significantly higher today than they were a decade ago, a result of lower leverage in CLO 2.0 transactions.

Panel B shifts attention to the liability side of the CLO balance sheet, presenting the fraction of originally issued debt outstanding over time. We split the data into the five most recent vintages for each crisis to show differential effects by age since issuance. The main takeaway from Panel B is that the debt financing of CLOs is resilient to even large fluctuations in the market value of collateral; any reductions in debt balances occur gradually 
after the shock to collateral values. These reductions occur when coverage tests are breached due to rating downgrades and defaults in the collateral pool, leading to the diversion of cash flows to pay down senior tranche principal. In both crises, we observe that more recently issued deals experience smaller reductions in debt financing because they had less time to experience collateral deterioration before the shock occurred. ${ }^{14}$

Panel $\mathrm{C}$ shows that equity distributions also respond gradually to market value shocks, despite the insolvent condition of most CLO balance sheets in late 2008 and early 2009. In the second and third quarters of 2009, the average distribution for the 2005-2007 vintages was down by two-thirds from the pre-crisis peak, while distributions for the 2003 and 2004 vintages approached zero. In fact, the median outstanding CLO paid nothing to equity investors in these quarters due to widespread coverage test failures. However, distributions rebounded to their pre-crisis level by mid-2010 and only improved from that point, as we saw in Figure 4. Due to the shorter and less severe shock to fundamentals in the Covid-19 crisis, we see only a small dip in equity payouts in the third quarter of 2020.

The evidence presented here and the strong performance of CLO 1.0 transactions highlight the resilience of the CLO structure to market volatility. This resilience is due to several features. First, CLOs are closed-end vehicles in which capital inflows and outflows are limited. Second, coverage tests are based on par values and credit ratings instead of market prices. Consequently, market volatility does not cause the diversion of cash flows to pay down debt tranches unless the volatility coincides with rating downgrades and defaults. Third, embedded options to reinvest collateral and reissue debt after a non-call period enable opportunistic trading and refinancing by CLO managers. Finally, CLOs employ a long-term funding structure known as "term leverage" that insulates the vehicle from rollover risk.

Unlike most levered investment vehicles that rely on short-term debt (e.g., banks, hedge funds), CLOs issue long-term debt with maturities in excess of seven years and fixed credit

\footnotetext{
${ }^{14}$ In the fourth quarter of 2007, the average CLO in the 2005-2007 vintages had 5\% more book value overcollateralization, equal to the par value of collateral divided by the face value of debt tranches, than CLOs in the 2003-2004 vintages.
} 
spreads. This feature became particularly valuable during the financial crisis, when many institutional investors taking levered positions were forced to reduce leverage or liquidate their positions (Mitchell and Pulvino (2012)). In contrast, CLO managers were able to maintain a highly levered position through the crisis without any increase in their debt servicing costs due to the long maturity of CLO securities. When markets recovered, this levered position paid off handsomely.

\subsection{The Role of Embedded Options}

The evidence presented thus far suggests an important role for embedded options in the CLO structure. In particular, the relatively strong performance of CLO 1.0 equity tranches appears to be driven by the ability to reinvest loan principal payments in higher-yielding collateral during market downturns. Likewise, CLO equity investors may benefit from the opportunity to refinance or reset liabilities to lower financing costs. In this section, we attempt to quantify the role of these embedded options in determining equity performance.

We construct counterfactual streams of equity distributions under two scenarios: one with no reinvestment of collateral proceeds, and one with no ability to refinance debt tranches. For the no-reinvestment case, we assume that loan spreads in the collateral pool are fixed after issuance and set the collateral spread equal to the value-weighted collateral spread in the first trustee report after the closing date. We compute distributions by scaling collateral interest payments by the ratio of the counterfactual coupon rate to the realized coupon rate, then subtracting the reduction in collateral cash flow from the realized equity distribution. The no-refinancing case is constructed in a similar manner, fixing debt tranche spreads at their initial level and subtracting the additional debt tranche interest from the realized equity distribution. Under both scenarios, a floor of zero is set on the counterfactual equity payout.

Figure 6 compares the median realized equity payout to the two counterfactual scenarios. Panel A shows that reinvestment had little impact on CLO 1.0 transactions before the financial crisis, but in the post-crisis period, approximately one-third of realized equity dis- 
tributions were attributable to reinvestment in higher-yielding collateral. Refinancing has no impact on CLO 1.0 transactions because they never had an opportunity to reissue debt tranches at lower spreads.

Panel B shows that reinvestment had a slightly negative impact on CLO 2.0 distributions because collateral spreads were declining over the life of early CLO 2.0 deals. However, many of these deals were able to refinance because CLO debt tranche spreads also decreased over this period, resulting in higher realized equity distributions.

Table 5 uses the GPME framework to quantify the impact of reinvestment and refinancing on the risk-adjusted performance of CLO equity. Consistent with the importance of collateral reinvestment for CLO 1.0 transactions, we observe a reduction in NPV of between 10 cents and 28 cents per dollar of equity investment. However, the no-reinvestment GPMEs remain economically and statistically significant - between 28 cents and 39 cents per dollar of equity after fees, or between 59 cents and 83 cents per dollar before fees. This suggests that opportunistic reinvestment during the financial crisis is not the sole driver of abnormal CLO equity performance in our sample.

The ability to refinance liabilities has a negligible effect on our GPME estimates because few of the completed CLOs in our sample were refinanced. However, this type of optionality will surely play a bigger role for the many CLO 2.0 transactions that have been refinanced but remain outstanding at the end of our sample period.

Before moving on, we should note the limitations of this counterfactual exercise. First, we do not account for the impact of removing options on the pricing of debt tranches. Both reinvestment and refinancing benefit equity investors at the expense of debt investors, so we would expect lower debt tranche spreads and higher equity distributions under the counterfactuals. In that light, the reduction in equity distributions could reflect an upper bound on the true effect. Second, maintaining a fixed collateral spread over the life of a CLO is infeasible due to the long maturity of CLOs relative to the underlying loans. This is apparent from the negative effect of reinvestment on CLO 2.0 cash flows, which would not 
occur if reinvestment were only opportunistic in nature. In sum, the counterfactual results should be viewed as guideposts rather than precise depictions of how embedded options affect CLO performance.

\section{Economic Mechanisms behind CLO Performance}

This section examines potential explanations for the risk-adjusted pricing differential between CLO collateral and debt tranches that results in abnormal performance for CLO equity tranches. We begin by exploring the role of regulatory incentives and credit rating agencies in affecting the pricing of CLO liabilities. We then investigate explanations related to the asset side of the CLO balance sheet, including managerial skill in collateral selection and trading, adverse selection, and moral hazard.

\section{$5.1 \quad$ Regulatory Incentives}

As noted above, senior debt tranches are responsible for the bulk of CLO funding and are held primarily by commercial banks, as well as some insurance companies. One plausible explanation for our findings is that these investors pay a premium for highly-rated CLO debt relative to leveraged loans because the former mitigate regulatory costs.

CLOs can be thought of as counterparties to banks that want to sell risky loans and buy safe bonds. This transaction confers several benefits to banks. First, the removal of risky assets and the corresponding high regulatory capital charges frees up capital so banks can originate additional loans. Second, CLO issuance provides the largest banks an opportunity to underwrite CLO securities, thereby generating additional fee income. Finally, CLOs create AAA-rated securities that come with relatively low regulatory capital charges. ${ }^{15}$

Highlighting the importance of the last point, banks and insurance companies provide the bulk of funding for CLO senior tranches (DeMarco, Liu, and Schmidt-Eisenlohr (2020),

\footnotetext{
${ }^{15}$ While loan mutual funds also serve as counterparties for loan sales, they offer neither underwriting opportunities nor highly-rated securities.
} 
Foley-Fisher, Heinrich, and Verani (2020)). To shed light on the appeal of CLO debt tranches to these regulated investors, we examine their performance relative to alternative debt instruments with similar capital requirements. Table 6 presents two measures of economic returns for debt tranches grouped by credit rating at issuance over the full sample and the CLO 1.0 and 2.0 eras. $^{16}$

Panel A presents internal rates of return (IRRs). Average IRRs are monotonically related to tranches' initial ratings, reflecting compensation for credit risk, and range from $2.3 \%$ for AAA-rated tranches to $6.7 \%$ for B-rated tranches over the full sample. IRR volatilities follow a similar pattern and are inversely related to credit rating. These patterns hold across the CLO 1.0 and 2.0 eras, though the latter period exhibits average IRRs that are more than $0.8 \%$ higher for tranches rated between $\mathrm{AA}$ and $\mathrm{BBB}$.

Panel B presents PMEs in the same format as Panel A. For CLO debt tranches, corporate bonds with the same credit rating are a natural benchmark, but they suffer from a duration mismatch that creates different exposures to interest rate changes. Recall that CLO tranches are floating-rate instruments with an effective duration of less than one year. In contrast, corporate bonds are fixed-rate instruments with an average maturity of 10 years, or approximate duration of seven years.

To address this mismatch, we construct synthetic floating-rate corporate bond returns by swapping the fixed coupon payments into floating payments using interest rate swaps. This calculation assumes an investor buys the corporate bond at issuance and enters into a payer swap. We calculate daily returns on the synthetic floating-rate bonds using the actual returns of fixed-rate corporate bonds and mark-to-market payer swap returns based on changes in the interest rate swap curve. For bonds that default or exit the sample, the swap is unwound at its mark-to-market value on the exit date. We compute benchmark indices for each rating

\footnotetext{
${ }^{16}$ In the Internet Appendix, we present evidence on debt tranche performance in terms of credit rating changes. All classes of debt experienced sharp downgrades in the financial crisis, but most tranches recovered to their original rating, and some mezzanine tranches were even upgraded above their original ratings. Outside of the financial crisis, CLO tranche ratings were stable over our sample period.
} 
category by value-weighting the synthetic floating-rate returns of individual bonds. ${ }^{17}$

Unlike IRRs, PMEs should not be correlated with the credit rating if the benchmark is accurately capturing risk. Nevertheless, the average PMEs are higher and the dispersion across deals is greater for lower-rated tranches. Comparing PMEs across the two subperiods, we see similar distributions, except for the B-rated CLO 1.0 tranches, of which there are only six observations, including one that defaulted during the Great Recession.

One distinguishing feature of the estimated PMEs is that every average is greater than one. In the full sample and both subperiods, nearly all of these estimates are statistically different from one at the $1 \%$ level using the spatial GMM framework from Korteweg and Nagel (2016). Furthermore, the 25th percentile is greater than or equal to one across all rating categories and both the CLO 1.0 and CLO 2.0 eras. Overall, the PME estimates suggest that CLO tranches have earned higher returns than synthetic floating-rate corporate bonds with the same credit rating.

To put the PMEs in the context of returns, we compute the difference between the IRR and the benchmark return over the same period. Senior tranches, rated AAA, earn about $0.5 \%$ more per year than similarly rated floating-rate corporate bonds. This return differential increases for lower-rated tranches, with mezzanine tranches, rated AA to BBB, earning $0.9 \%$ to $1.4 \%$, and junior tranches, rated BB and B, earning $1.8 \%$ to $2.3 \%$ more than their respective benchmarks.

Although the results in Table 6 are suggestive of outperformance, the GPME analysis in Table 4 suggests that debt tranches earn normal or even abnormally low risk-adjusted returns. It is likely that the high returns relative to corporate bonds are due to differential risk factors not captured by the PME adjustment. CLO tranches are more exposed to systematic risk than corporate bonds issued by individual firms because a widespread economic downturn, involving defaults by firms in several industries, is necessary for CLO

\footnotetext{
${ }^{17}$ For the AAA benchmark, we include both AAA and AA rated corporate bonds, because very few corporate issuers are rated AAA. Our results are robust to including only AAA-rated bonds in the benchmark. Details on the synthetic floating-rate corporate bond returns are provided in the Internet Appendix.
} 
debt to become impaired. Coval, Jurek, and Stafford (2009) describe these as "economic catastrophe bonds" and note that credit ratings only account for the probability of default, rather than the states of the economy in which default occurs. Therefore, the high returns of CLO tranches could be explained by compensation for systematic risk exposure (Elkamhi, Li, and Nozawa (2020)). Consistent with this interpretation, the realized default rate of CLO tranches is significantly lower than the default rate on corporate bonds over our sample period (Standard \& Poor's (2014), Moody's (2020)), which suggests that the "catastrophe" necessary to cause CLO defaults has not yet occurred, an issue on which we elaborate below.

Illiquidity and prepayment risk are additional differences that could be responsible for the relatively high returns of CLO debt tranches. The secondary market for CLO tranches is opaque, but Hendershott et al. (2020) provide evidence on its liquidity using regulatory data. Although CLOs have lower bid-ask spreads than corporate bonds, they trade much less frequently and have higher costs of failed trades. Finally, CLO debt is almost always callable, with a standard non-call period of between six months and two years (Standard \& Poor's (2018)). In contrast, Becker et al. (2021) show that only one-fifth of investment-grade corporate bonds have a call feature, while three-quarters of non-investment-grade corporate bonds are callable. As noted above, we track each tranche from origination through any refinancing events, so all else equal, a debt tranche that is refinanced to reduce its spread will have lower returns than a tranche that is not.

As an additional lens on the relative performance of CLO senior tranches, Internet Appendix Table A10 presents PME estimates for AAA-rated CLO tranches relative to AAArated ABS tranches. We find that CLO senior tranches offer significantly higher returns than an index of ABS senior tranches including auto, credit card, and student loan securitizations. The full sample PME estimate corresponds to a return difference of about $0.8 \%$ per year. This comparison is useful because ABS tranches are even closer substitutes for CLO tranches than corporate bonds, though differences remain - ABS have shorter effective maturities, static collateral pools, and different underlying risk exposures. 
In sum, CLO debt tranches offer high returns relative to similarly rated alternatives, which helps to explain the high risk-adjusted price they command relative to CLO collateral. Banks and insurance companies, which are responsible for purchasing the majority of senior CLO debt, face capital requirements that are directly tied to credit ratings. This regulation creates two distinct incentives that increase demand for CLO tranches. First, these intermediaries prefer safer assets to riskier assets, which face higher capital charges, to relax their capital constraints. Indeed, Irani et al. (2020) show that banks' incentives to sell risky loans are directly linked to their capitalization ratios. Second, banks and insurers "reach for yield" (Becker and Ivashina (2015), Merrill, Nadauld, and Strahan (2019)) by selecting the highest-yielding debt instruments in a rating category.

\subsection{Ratings Inflation}

Another potential source of equity abnormal returns comes from ratings inflation (Griffin and Nickerson (2020)). If CLO debt tranche ratings underestimate default risk, than debt investors may be lured into overpaying for what they incorrectly believe are safer securities. At first glance, several of our results are consistent with this explanation.

Arguably, ratings inflation would be at its worst prior to the financial crisis, after which the rating agencies revamped their securitization rating protocols. As discussed earlier and shown in Figure 3, CLOs responded to these changes, as well as investor demand, by increasing subordination levels for senior debt tranches and reducing overall leverage for CLO 2.0 transactions. Thus, mispricing due to ratings inflation would be greatest among CLO 1.0 deals, exactly where we see the best equity performance.

However, a closer look at historical default rates reveals that CLO debt tranches default at a much lower rate than equivalently rated corporate debt. Table 7 presents default rates

for CLO debt tranches and corporate bonds by credit rating. Apparent in both the CLO 1.0 and 2.0 eras are the materially lower default rates for CLO debt tranches relative to corporate bonds in the same rating category. The steady performance of CLO 1.0 debt 
tranches through the financial crisis contrasts starkly with the widespread default of AAArated ABS CDO tranches during that period (Cordell, Feldberg, and Sass (2019)). Overall, this body of evidence is inconsistent with the inflation of credit ratings in the CLO market. ${ }^{18}$

\subsection{Skill in Selecting and Trading Loans}

Another explanation for the abnormal equity returns is that managers have private information or skill in selecting and trading loans. To assess this hypothesis, we require information on collateral cash flows and fees. Because data on the cash flows generated by CLO collateral are sparsely populated in Intex, we exploit the balance sheet identity to compute the after-fee cash flows of CLO collateral as the sum of distributions to all CLO debt and equity tranches. Before-fee cash flows are computed as the sum of after-fee cash flows and management fees. ${ }^{19}$

We assess the performance of CLO collateral using PME estimates against two benchmarks for the leveraged loan market. The first benchmark is the S\&P/LSTA U.S. Leveraged Loan 100 Index, which has a correlation of 0.99 with a value-weighted portfolio of all leveraged loans in the IHS Markit Loan Pricing database. This index serves as a benchmark for before-fee cash flows. The second benchmark is a value-weighted return of loan mutual funds in the Morningstar Direct and CRSP databases, which serves as an investable benchmark for after-fee cash flows. We emphasize that these benchmarks are chosen to test whether CLO collateral earns high returns relative to other leveraged loans and not to make statements concerning risk-adjusted performance.

\footnotetext{
${ }^{18} \mathrm{It}$ is possible that CLO ratings are inflated and we have yet to experience the economic shock revealing the inflation, despite our sample including the Great Recession and the first year of the Covid-19 crisis. Nonetheless, the default rates suggest that ratings inflation is unlikely to be responsible for the observed performance of CLOs in our sample.

${ }^{19}$ Our estimates of collateral cash flows may be biased downward for several reasons, including unobserved payments (taxes, administrative fees, petition fees, hedge payments), the use of collateral interest to purchase additional collateral in the event of coverage test or tranche rating impairment during the reinvestment period, or the use of collection and supplemental reserve accounts. Importantly, any downward bias in collateral cash flows implies that the true difference in pricing relative to debt tranches is even larger than estimated in Table 4. In the Internet Appendix we provide alternative tests of informed trading by CLO managers, which we discuss below.
} 
Table 8 reports the PME estimates for CLO collateral distributions by era and for the entire sample. Panel A shows that gross of management fees, CLO collateral pools generate cash flows that are slightly lower than the return of the leveraged loan market. The overall average PME of 0.98 implies that one dollar invested in CLO collateral would generate the same cash flows as 98 cents invested in the leveraged loan index over our sample period. To test whether the PME is statistically different from one, we construct a $J$-test using the spatial GMM covariance matrix from Korteweg and Nagel (2016), which accounts for correlated performance across deals by assuming that correlation declines with the degree of overlap in their time windows. We find that the PME is statistically significant at the $1 \%$ level, indicating that CLO collateral has statistically underperformed the loan index.

The pre- and post-crisis eras - CLO 1.0 and CLO 2.0 - lead to a similar conclusion. Though the CLO 1.0 vehicles exhibit statistically significant underperformance relative to the LSTA Index (0.97), the difference is economically small and insignificantly different from both the CLO 2.0 and overall averages (0.98). One potential explanation for this slight underperformance is the underestimation of gross cash flows from the collateral pool due to underestimation of management fees or failure to capture other deal expenses.

Panel B presents analogous results for after-fee collateral distributions relative to a valueweighted index of loan mutual funds. For context, the average mutual fund in our sample has an annual fee of 62 bps of assets under management, slightly higher than the typical CLO. The average PMEs for the whole sample and across CLO 1.0 and 2.0 eras show no statistically or economically significant difference from one. Thus, in aggregate, CLO collateral offers similar returns to a value-weighted index of leveraged loans.

To provide further evidence on the question of managerial skill, we examine loan-level returns after collateral trading decisions made during the reinvestment period of the CLO. If CLO managers are skilled at collateral selection, we expect collateral purchases to have higher excess returns than collateral sales. The results, contained in Internet Appendix Table A9, reveal no economically significant difference between the post-trade excess returns 
of purchases and sales. ${ }^{20}$ In sum, neither the portfolio returns nor the trading activity of the average CLO appear to be driven by a unique skill or informational advantage relative to other loan market participants.

\subsection{Imperfect Information}

\subsubsection{Adverse Selection}

Imperfect information is commonly used to rationalize securitization (e.g., Glaeser and Kallal (1997), Riddiough (1997), and DeMarzo (2005)). The canonical example involves a bank attempting to sell mortgages or credit card debt to investors worried about receiving credits that are of worse quality than they appear. In DeMarzo (2005), pooling and tranching takes advantage of risk diversification to create a liquid security that mitigates the "lemons" problem arising from the bank's informational advantage.

An important difference between traditional securitizations and CLOs is that the vast majority of CLOs are open-market vehicles in which the manager does not originate the loans in the collateral pool. Rather, loans are acquired through participations or purchases on the secondary market. This feature of CLOs has led the courts to rule that CLOs are not securitizations for the purpose of risk-retention rules under the Dodd-Frank Act. ${ }^{21}$ Indeed, some of the investors in AAA-rated CLO debt tranches are the very banks that originated the loans in the asset pool - behavior that is difficult to rationalize with information asymmetry.

This legal distinction is supported by empirical evidence from Benmelech, Dlugosz, and Ivashina (2012), who argue that "the securitization of corporate loans is fundamentally

\footnotetext{
${ }^{20}$ While CLO managers earn marginally statistically significant abnormal returns over the week after a loan purchase, the magnitude $(0.24 \%)$ is equivalent to one-fifth of the mean bid-ask spread $(1.25 \%)$ in the IHS Markit data. The abnormal return shrinks and becomes statistically insignificant at a three-month horizon.

${ }^{21}$ This distinction was central to the success of a lawsuit filed by the Loan Syndications and Trading Association against the Securities and Exchange Commission and the Federal Reserve Board arguing that CLO managers should be exempt from the risk retention rule imposed by the Dodd-Frank Act. The D.C. Circuit court ruled in February 2018 that open-market CLO managers are not "securitizers" as defined in the rule because these managers neither own nor control the asset that is transferred to the securitization vehicle. See Loan Syndications 63 Trading Ass'n v. SEC, 223 F. Supp. 3d 37 (D.D.C. 2016).
} 
different from securitization of other asset classes because securitized loans are fractions of syndicated loans." These authors show that syndicated loans that were securitized before the financial crisis performed no differently from otherwise similar loans that were not securitized.

While adverse selection may not be pervasive among CLOs holding broadly syndicated loans, the large majority of deals in our sample, it may play a role for middle-market CLOs. Recall that in middle-market deals, the CLO manager originates loans to small- and mediumsize companies and includes them in the CLO collateral pool. Thus, there is greater scope for an information gap between the CLO manager and CLO investors.

Consistent with the effects of adverse selection, in the Internet Appendix we show that middle-market deals exhibit higher collateral and equity performance as measured by IRR, PME, and GPME estimates, though the small number of completed middle-market deals (51) leads to statistically insignificant differences. While suggestive of adverse selection playing a role in the middle-market segment, a more thorough analysis akin to that performed by Benmelech, Dlugosz, and Ivashina (2012) is needed to provide more compelling evidence. Given the focus of this study, adverse selection does not appear to be a first-order explanation of our findings on CLO performance.

\subsubsection{Moral Hazard}

Our results could also be construed as consistent with a moral hazard problem in which, despite protective covenants, CLO managers trade into riskier collateral after origination to expropriate debtholders. The result would be positive abnormal equity performance at the expense of debtholders, who would earn negative abnormal returns. The temporal variation in our results is consistent with this, if one believes that tighter rating standards and lower leverage in the CLO 2.0 era have mitigated the problem. However, more direct evidence casts doubt on the moral hazard hypothesis.

Investor funds are not delivered until most of the collateral pool is formed and funded with a warehouse facility. Therefore, any expropriation is more likely to occur through post- 
issuance trading behavior. To test this hypothesis, we examine the risk profiles of collateral pools in event time after issuance using the residuals from a regression of loan spreads on calendar quarter and vintage group fixed effects. If managers are shifting into riskier credits, then we should see an increase in these residuals over the deal life cycle. Figure 7 plots the residual loan spreads in event time and shows that, if anything, they tend to decrease over the life of a CLO. Thus, agency conflicts among CLO stakeholders do not appear to be behind our performance results. ${ }^{22}$

\section{Conclusion}

This paper provides novel evidence on the market imperfections responsible for the widespread securitization of corporate loans by examining the performance of CLO assets and liabilities. We show that CLO equity earns abnormal positive returns by exploiting risk-adjusted price differentials between the market for leveraged loans and the market for CLO debt securities. This surplus does not come from managerial skill in selecting leveraged loans, though there is heterogeneity in performance across managers. The average CLO collateral pool offers similar returns to a broad index of leveraged loans or a portfolio of loan mutual funds. Rather, what distinguishes CLO managers appears to be their access to risk-bearing capital, particularly that supporting the equity tranche.

We also find that CLO equity exhibits a great deal of resilience to market volatility, with the best-performing vintages issued just prior to the financial crisis. Similar resilience is observed during the first year of the Covid-19 crisis. This resilience is due to the longterm, closed-end financing structure of CLOs, which provides equity investors with a levered position insulated from capital outflows and rollover risk.

CLO debt earns higher returns than similarly rated and duration-matched corporate bonds but underperforms CLO collateral on a risk-adjusted basis. This distinction is due to

\footnotetext{
${ }^{22}$ These results are consistent with Fabozzi et al. (2021), who find that more active trading by CLO managers is associated with lower collateral portfolio default rates.
} 
the failure of credit ratings to capture systematic, liquidity, and prepayment risks. Nonetheless, high-yielding assets within a credit rating are particularly attractive to the banks and insurers that provide the bulk of funding for CLOs.

Despite the progress made here, important questions remain. How will outstanding CLOs perform through the remainder of the Covid-19 crisis and beyond? Will the CLO market continue its rapid growth after the resumption of issuance in mid-2020? What are the implications of this growth, or lack thereof, for corporate borrowers, CLO investors, and financial stability? Finally, what are the broader welfare effects of CLOs? Our analysis focuses on the gains to CLO managers and investors, but the equilibrium effects on corporate borrowing costs and the potential risks of regulatory arbitrage by intermediaries remain open issues. We look forward to future research that addresses these and other related questions. 


\section{References}

Acharya, Viral V., and Matthew P. Richardson, 2009, Causes of the financial crisis, Critical Review $21,195-210$.

An, Xudong, Yongheng Deng, and Stuart A. Gabriel, 2011, Asymmetric information, adverse selection, and the pricing of CMBS, Journal of Financial Economics 100, 304-325.

Becker, Bo, and Victoria Ivashina, 2015, Reaching for yield in the bond market, Journal of Finance 60, 1863-1901.

Becker, Bo, Maurillo Campello, Viktor Thell, and Dong Yan, 2021, Debt overhang and the life cycle of callable bonds, Working paper, Stockholm School of Economics.

Benmelech, Efraim, and Jennifer Dlugosz, 2009, The alchemy of CDO credit ratings, Journal of Monetary Economics 56, 617-634.

Benmelech, Efraim, Jennifer Dlugosz, and Victoria Ivashina, 2012, Securitization without adverse selection: The case of CLOs, Journal of Financial Economics 106, 91-113.

Bord, Vitaly M., and Joao A.C. Santos, 2015, Does securitization of corporate loans lead to riskier lending? Journal of Money, Credit, and Banking 47, 415-444.

Brennan, Michael J., Julia Hein, and Ser-Huang Poon, 2009, Tranching and rating, European Financial Management 15, 891-922.

Chernenko, Sergey, 2017, The front men of Wall Street: The role of CDO collateral managers in the CDO boom and bust, Journal of Finance 72, 1893-1936.

Collin-Dufresne, Pierre, Robert S. Goldstein, and Fan Yang, 2012, On the relative pricing of longmaturity index options and collateralized debt obligations, Journal of Finance 67, 1983-2014.

Constantinides, George M., 1986, Capital market equilibrium with transaction costs, Journal of Political Economy 94, 842-862.

Cordell, Larry, Greg Feldberg, and Danielle Sass, 2019, The role of ABS CDOs in the financial crisis, Journal of Structured Finance 25, 10-27. 
Coval, Joshua, Jakub Jurek, and Erik Stafford, 2009, Economic catastrophe bonds, American Economic Review 99, 628-666.

DeMarco, Laurie, Emily Liu, and Tim Schmidt-Eisenlohr, 2020, Who owns U.S. CLO securities? An update by tranche, FEDS Notes, Federal Reserve Board of Governors, June 25, 2020.

DeMarzo, Peter M., 2005, The pooling and tranching of securities: A model of informed intermediation, Review of Financial Studies 18, 1-35.

DeMarzo, Peter M., and Darrell Duffie, 1999, A liquidity-based model of security design, Econometrica 67, 65-99.

Elkamhi, Redouane, Ruicong Li, and Yoshio Nozawa, 2020, A benchmark for collateralized loan obligations, Working paper, University of Toronto.

Elkamhi, Redouane, and Yoshio Nozawa, 2020, Fire-sale risk in the leveraged loan market, Working paper, University of Toronto.

Erel, Isil, Taylor Nadauld, and René M. Stulz, 2014, Why did holdings of highly rated securitization tranches differ so much across banks? Review of Financial Studies 27, 404-453.

Fabozzi, Frank J., Sven Klingler, Pia Molgaard, and Mads Stenbo Nielsen, 2021, Active loan trading, Journal of Financial Intermediation 46, 100868.

Foley-Fisher, Nathan, Nathan Heinrich, and Stephane Verani, 2020, Capturing the illiquidity premium, Working paper, Federal Reserve Board of Governors.

Glaeser, Edward L., and Hedi Kallal, 1997, Thin markets, asymmetric information, and mortgagebacked securities, Journal of Financial Intermediation 6, 64-86.

Griffin, John M., and Jordan Nickerson, 2020, Are CLO collateral and tranche ratings disconnected? Working paper, University of Texas.

Griffin, John M., and Dragon Y. Tang, 2012, Did subjectivity play a role in CDO credit ratings? Journal of Finance 67, 1293-1328. 
Harris, Robert S., Tim Jenkinson, and Steven N. Kaplan, 2014, Private equity performance: What do we know? Journal of Finance 69, 1851-1882.

He, Zhiguo, Bryan Kelly, and Asaf Manela, 2017, Intermediary asset pricing: New evidence from many asset classes, Journal of Financial Economics 126, 1-35.

Hendershott, Terrence, Dan Li, Dmitry Livdan, and Norman Schurhoff, 2020, True cost of immediacy, Working paper, University of California, Berkeley.

Irani, Rustom M., Rajkamal Iyer, Ralf R. Meisenzahl, and Jose-Luis Peydro, 2020, The rise of shadow banking: Evidence from capital regulation, Review of Financial Studies, forthcoming.

Ivashina, Victoria, and Zheng Sun, 2011, Institutional demand pressure and the cost of corporate loans, Journal of Financial Economics 99, 500-522.

Kaplan, Steven N., and Antoinette Schoar, 2005, Private equity performance: Returns, persistence, and capital flows, Journal of Finance 60, 1791-1823.

Korteweg, Arthur, and Stefan Nagel, 2016, Risk-adjusting the returns to venture capital, Journal of Finance 71, 1437-1470.

Kundu, Shohini, 2021, The externalities of fire sales: Evidence from collateralized loan obligations, Working paper, University of California, Los Angeles.

Liebscher, Roberto, and Thomas Mahlmann, 2017, Are professional investment managers skilled? Evidence from syndicated loan portfolios, Management Science 63, 1892-1918.

Longstaff, Francis A., and Brett W. Myers, 2014, How does the market value toxic assets? Journal of Financial and Quantitative Analysis 49, 297-319.

MarketWatch, 2019, Here's why the Fed and global regulators are ringing the alarm over leveraged loans and CLOs, March 12, 2019.

Merrill, Craig B., Taylor D. Nadauld, and Philip E. Strahan, 2019, Final demand for structured finance securities, Management Science 65, 390-412. 
Merton, Robert C., 1974, On the pricing of corporate debt: The risk structure of interest rates, Journal of Finance 29, 449-470.

Mitchell, Mark, and Todd Pulvino, 2012, Arbitrage crashes and the speed of capital, Journal of Financial Economics 104, 469-490.

Modigliani, Franco, and Merton H. Miller, 1958, The cost of capital, corporation finance and the theory of investment, American Economic Review 48, 261-297.

Moody's Investors Service, 2010, Moody's updated modeling parameters for rating corporate synthetic CDOs and cash flow CLOs.

Moody's Investors Service, 2018, Annual default study: Corporate default and recovery rates, 1920-2017.

Moody's Investors Service, 2020, Impairment and loss rates of global CLOs: 1993-2019.

Nadauld, Taylor D., and Michael S. Weisbach, 2012, Did securitization affect the cost of corporate debt? Journal of Financial Economics 105, 332-352.

Nickerson, Jordan, and John M. Griffin, 2017, Debt correlations in the wake of the financial crisis: What are appropriate default correlations for structured products? Journal of Financial Economics 125, 454-474.

Ospina, Juan, and Harald Uhlig, 2018, Mortgage-backed securities and the financial crisis of 2008: A post-mortem, Working paper, University of Chicago.

Pastor, Lubos, and Robert F. Stambaugh, 2003, Liquidity risk and expected stock returns, Journal of Political Economy 111, 642-685.

Peristiani, Stavros, and Joao A.C. Santos, 2019, CLO trading and collateral manager bank affiliation, Journal of Financial Intermediation 39, 47-58.

Riddiough, Timothy J., 1997, Optimal design and governance of asset-backed securities, Journal of Financial Intermediation 6, 121-152. 
Roberts, Michael R., and Michael Schwert, 2020, Interest rates and the design of financial contracts, Working paper, University of Pennsylvania.

Schwert, Michael, 2020, Does borrowing from banks cost more than borrowing from the market? Journal of Finance 75, 905-947.

Seo, Sang Byung, and Jessica A. Wachter, 2018, Do rare events explain CDX tranche spreads? Journal of Finance 73, 2343-2383.

Shivdasani, Anil, and Yihui Wang, 2011, Did structured credit fuel the LBO boom? Journal of Finance 66, 1291-1328.

Standard \& Poor's, 2014, Twenty Years Strong: A Look Back at U.S. CLO Ratings Performance from 1994 through 2013.

Standard \& Poor's, 2018, S\&P Global Ratings CLO Primer.

Standard \& Poor's, 2020a, COVID-19 poses risks to collateralized loan obligations, EU regulator warns, May 14, 2020.

Standard \& Poor's, 2020b, LCD's Quarterly Leveraged Lending Review: 2Q 2020.

Standard \& Poor's, 2021, CLO Spotlight: First CLO 2.0 Tranches Default in the Aftermath of Pandemic-Related Stresses.

Wang, Yihui, and Han Xia, 2014, Do lenders still monitor when they can securitize loans? Review of Financial Studies 27, 2354-2391. 
Figure 1: Intex Coverage of the CLO Market

This figure plots the total amount of CLOs outstanding in the Intex sample by year and compares it to the aggregate size of the U.S. CLO market. Aggregate market data are from the Securities Industry and Financial Markets Association (SIFMA) for years 1989 to 2019 and from JPMorgan Chase for 2020.

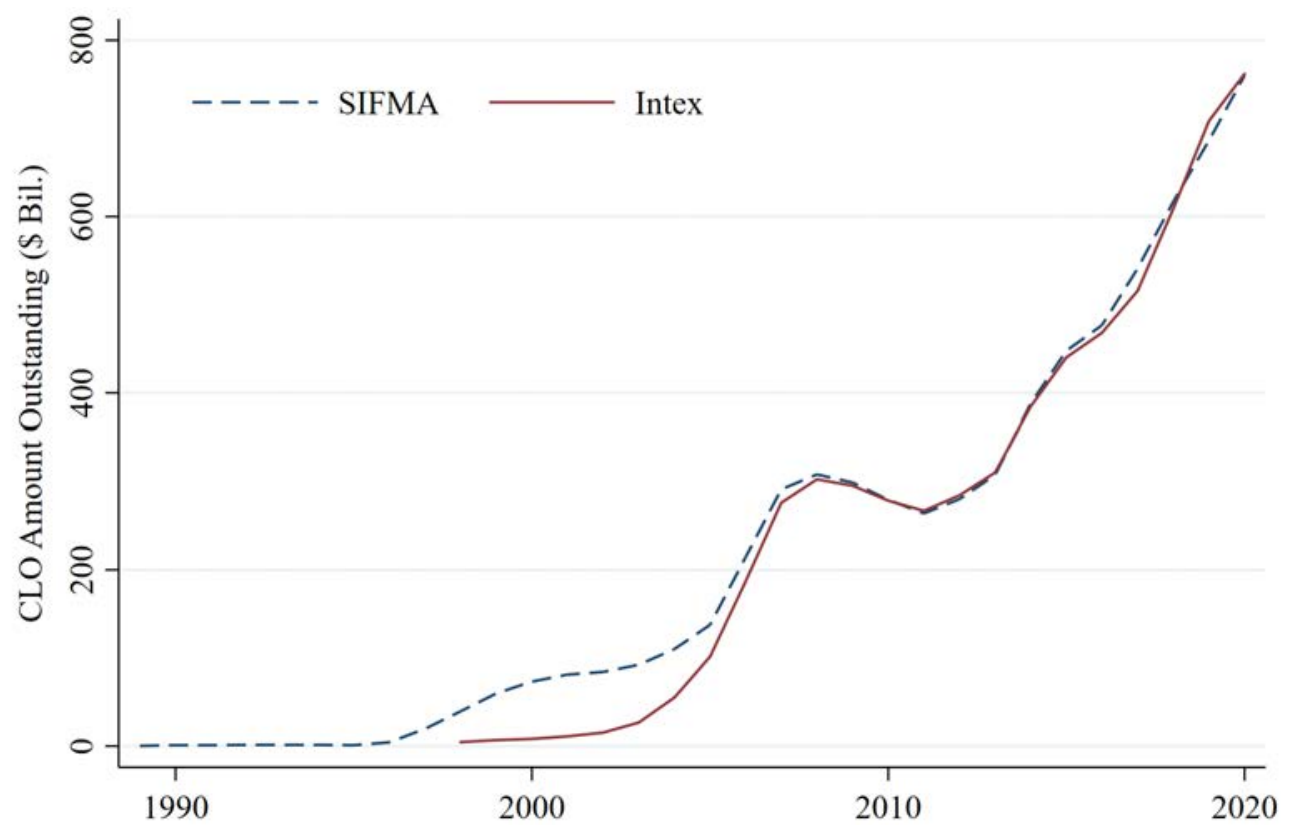


Figure 2: History of Management Fees

This figure presents the history of realized management fee payments by vintage group. The three groups are 2005-2009, 2010-2016, and 2017-2019. We do not have data on realized fees for deals issued before 2005. For each vintage group, we plot the median fee on an annual basis. Fees are reported as a fraction of the deal's collateral balance, in basis points. The sample is restricted to vintage-year observations with at least ten deals. Data on management fees are from Intex.

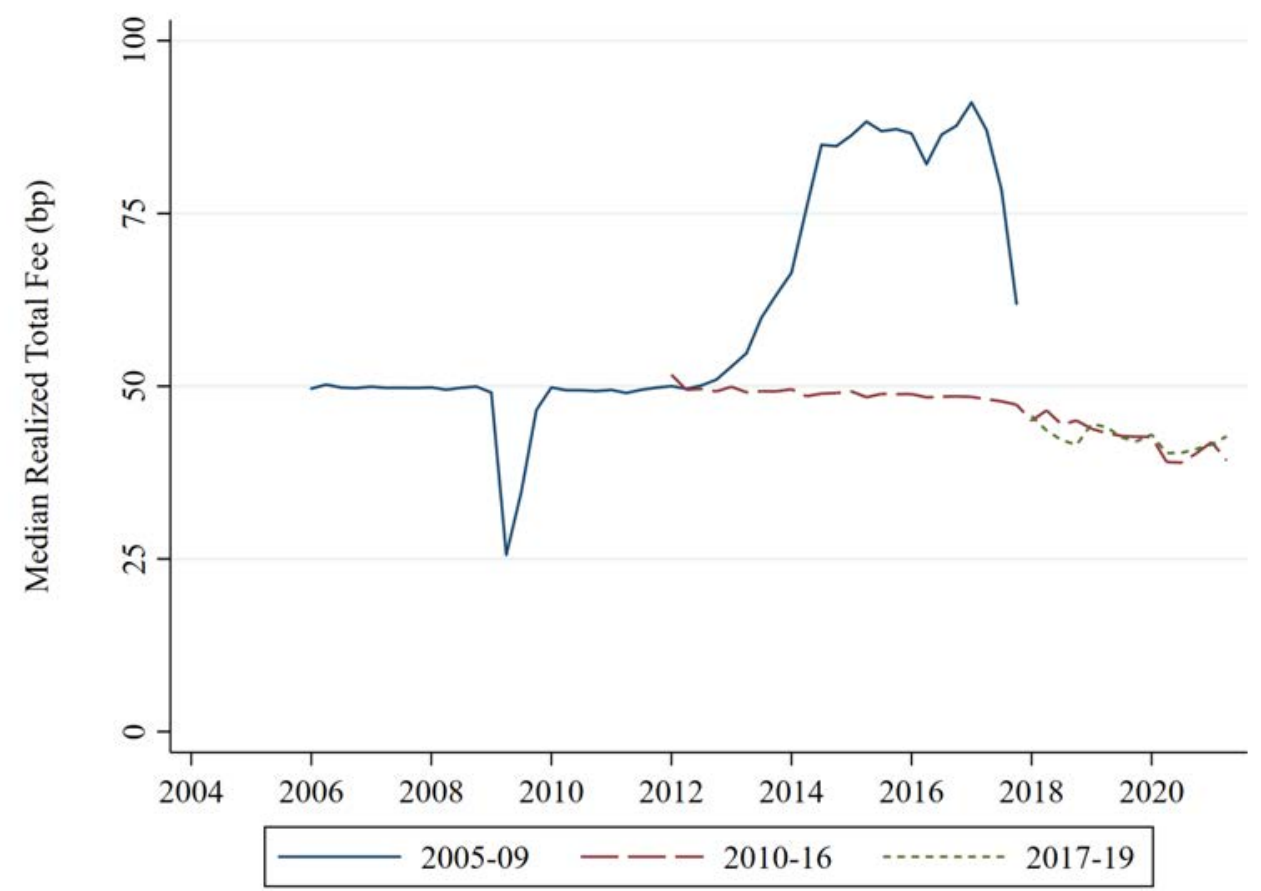




\section{Figure 3: CLO Balance Sheet}

This figure presents the composition of CLO collateral and liabilities by credit rating in our sample. We split the sample into CLO 1.0, deals issued before 2010, and CLO 2.0, deals issued from 2010 onward, to highlight changes in CLO structures over time. Collateral composition is presented as the principal value-weighted share of collateral by credit rating based on the first collateral report for each deal. We pool loans rated $\mathrm{BB}+$ and above and loans rated $\mathrm{CCC}+$ and below because they have relatively small shares. Liability composition is presented as the principal value-weighted share of liabilities by rating category at issuance. We pool the BB and B categories because they have relatively small shares. Data on collateral holdings and liability structure are from Intex.

Panel A: CLO 1.0

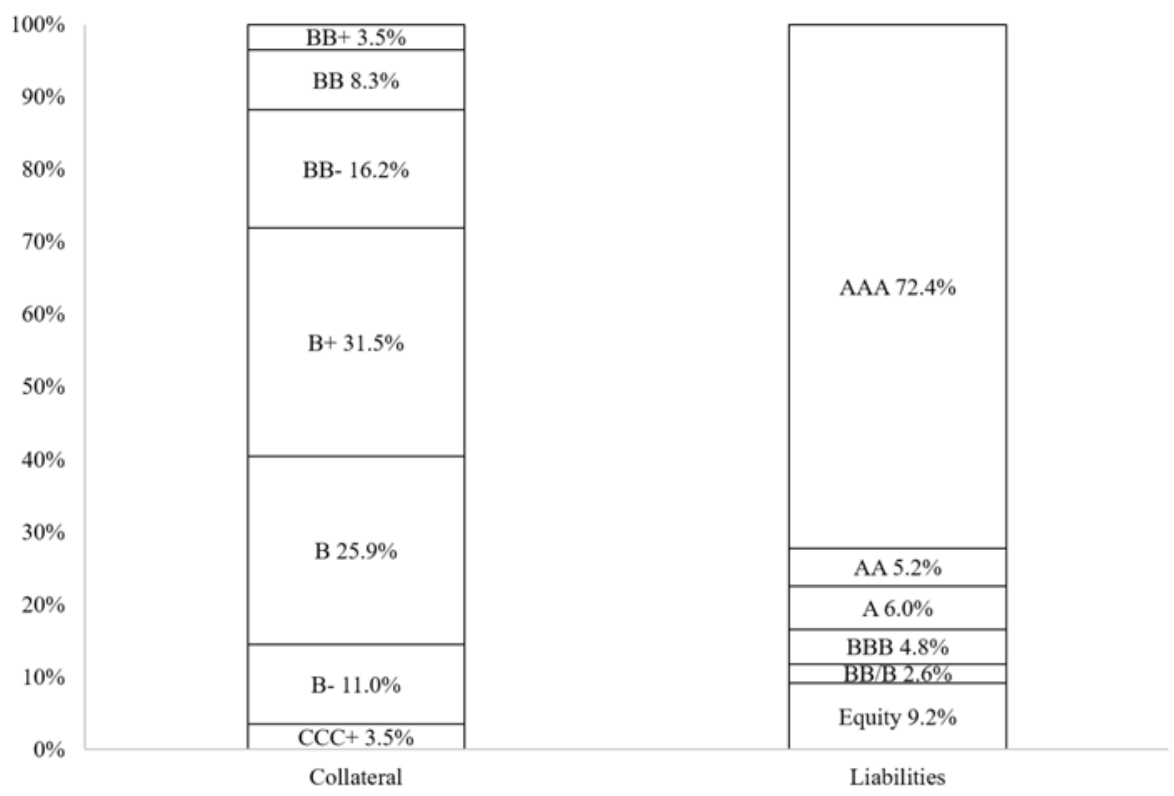

Panel B: CLO 2.0

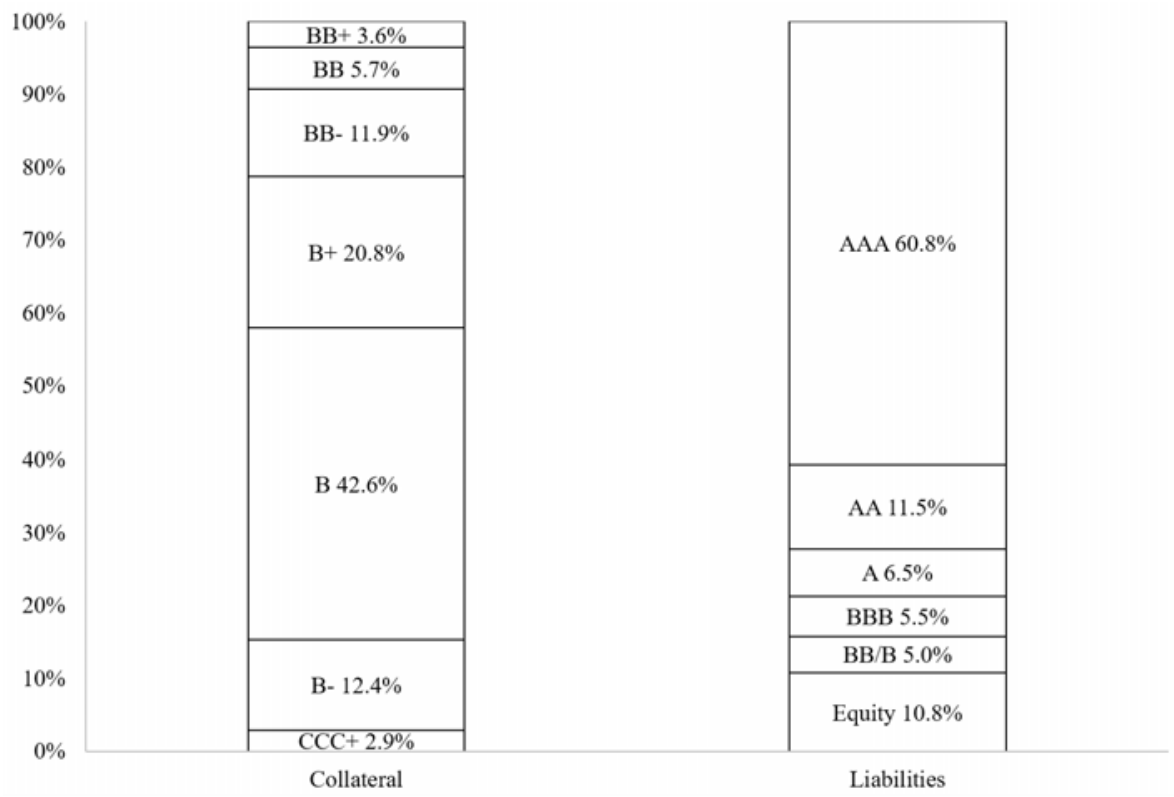


Figure 4: CLO Interest Rates and Cash Distributions

This figure presents debt and equity tranche distributions by vintage group. The four groups are 1997-2004, 2005-2009, 2010-2016, and 2017-2019. The first row reports the value-weighted mean coupon rate on loans in the collateral pool and debt tranches. The second row reports the median annualized distributions to equity tranches in calendar time and in event time relative to the deal's closing date. The sample is restricted to vintage-quarter observations with at least five deals and at least $25 \%$ of the initial debt outstanding. Distributions and tranche information are from Intex. Collateral coupon rates are computed using LIBOR rates from Bloomberg and loan spreads and LIBOR floors from IHS Markit for loans we can match to Intex. We fill in unmatched loans, primarily before 2005, using spreads from Intex under the assumption of no LIBOR floor.

Panel A: Collateral Coupon Rate

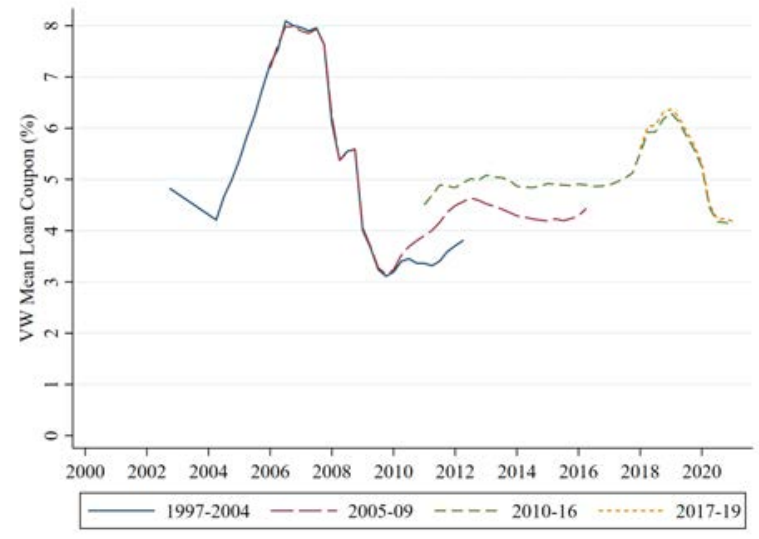

Panel C: Equity Payout in Calendar Time

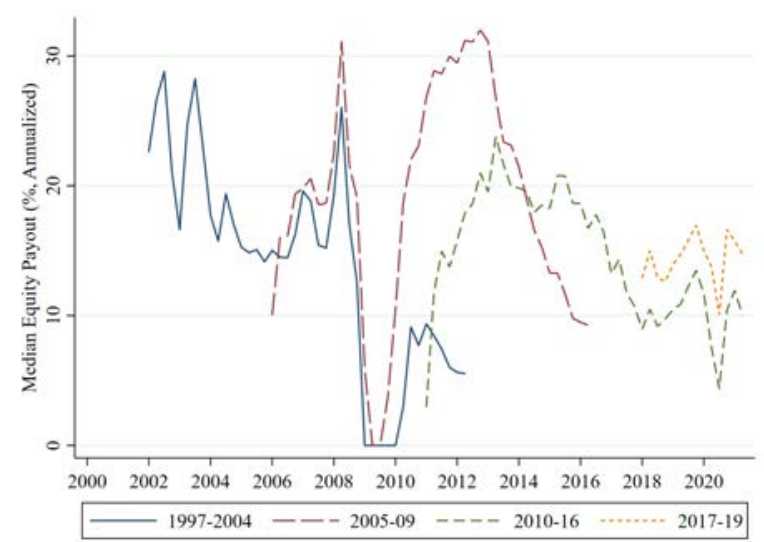

Panel B: Debt Tranche Coupon Rate

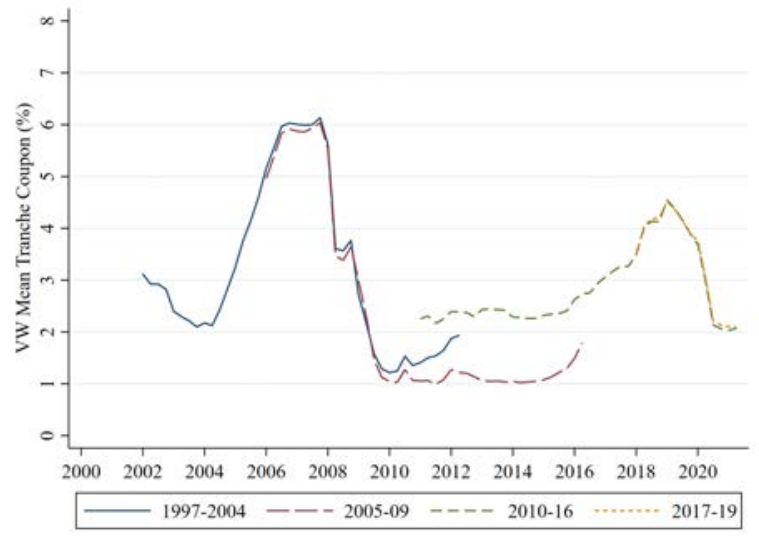

Panel D: Equity Payout in Event Time

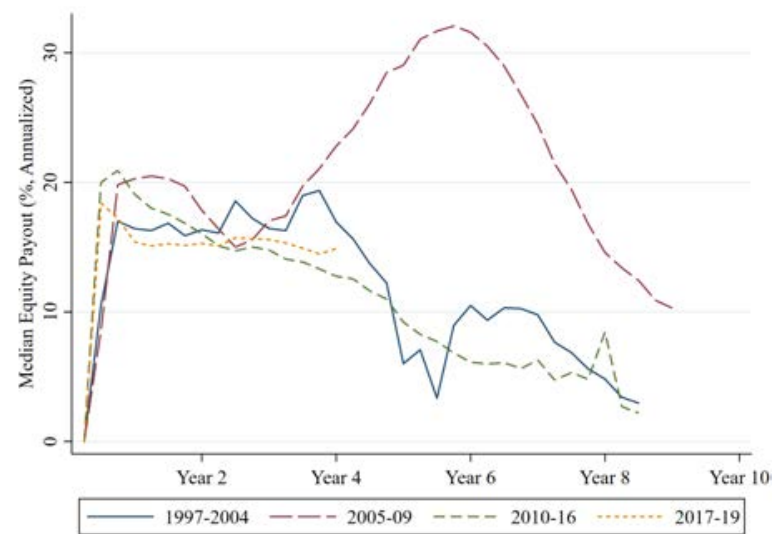


Figure 5: CLO Performance during the Financial and Covid-19 Crises

This figure plots the equity distributions and market value coverage ratios for CLOs outstanding around the financial crisis of 2008 (left column) and the Covid-19 crisis of 2020 (right column). Panel A reports median coverage ratios for CLO debt tranches by credit rating, where the coverage ratio is the market value of collateral divided by the face value of that tranche and all tranches senior to it. Panel B reports CLO debt outstanding as a fraction of original debt issued by vintage. Panel C reports principal value-weighted mean CLO equity distributions by vintage. Distributions and tranche information are from Intex and collateral prices are from IHS Markit.

Panel A: Market Value Coverage of Debt Tranches
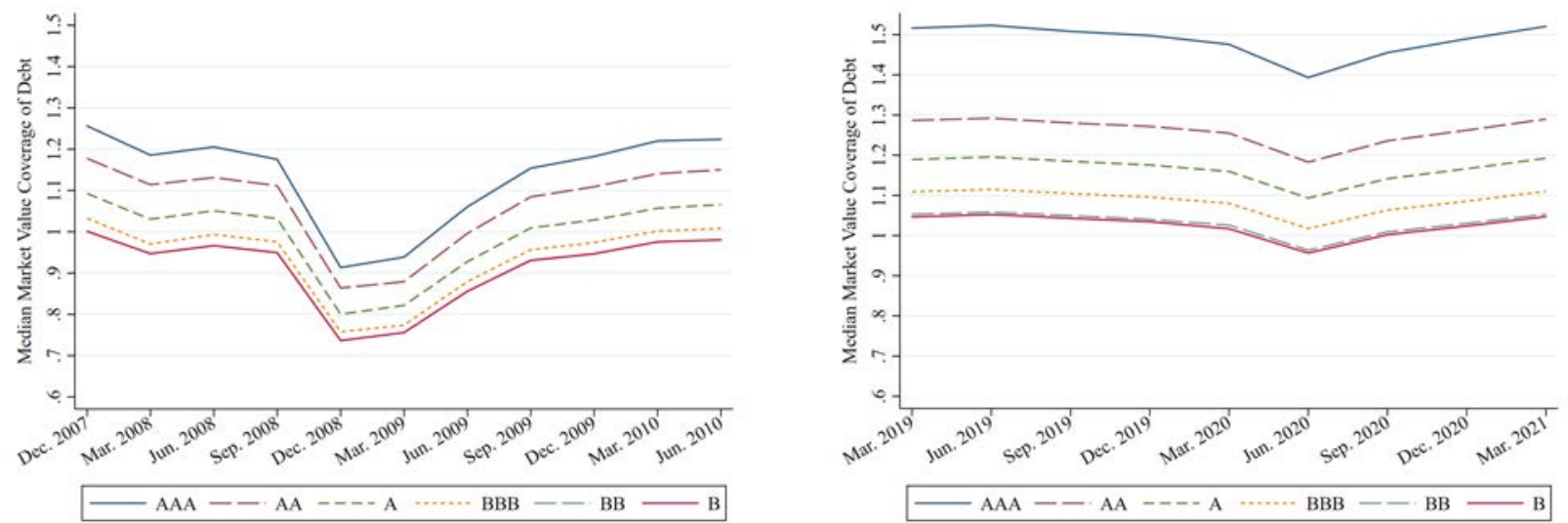

Panel B: Debt Outstanding as a Fraction of Original Issuance
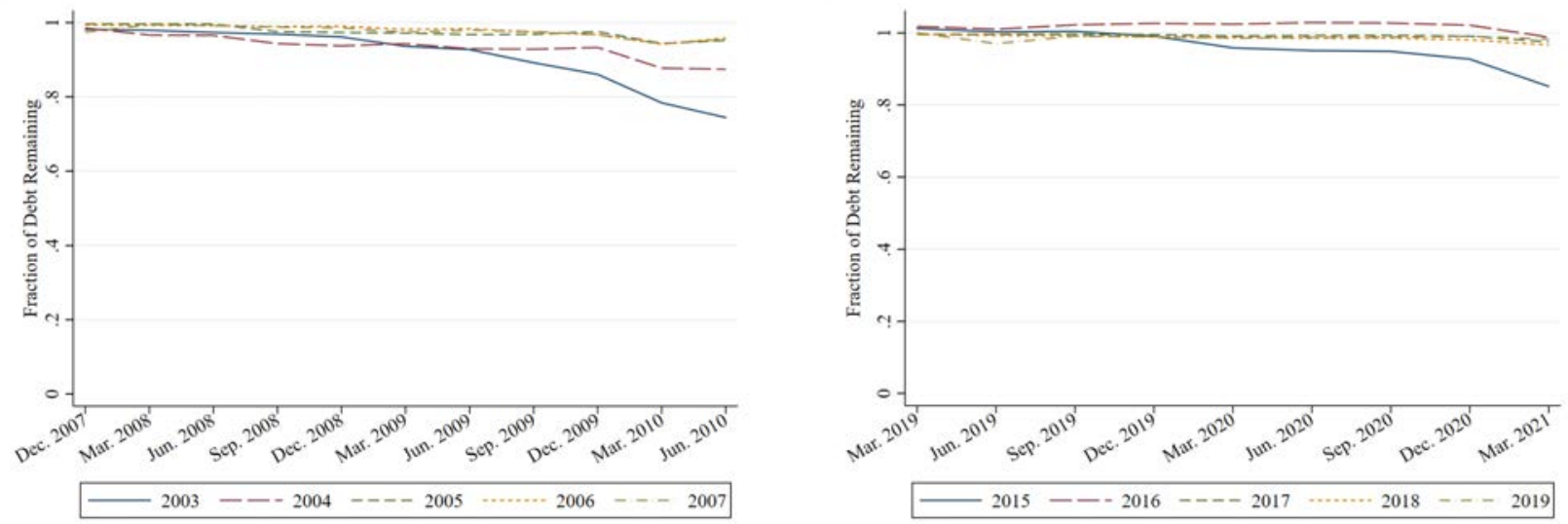

Panel C: Annualized Distributions to Equity Investors
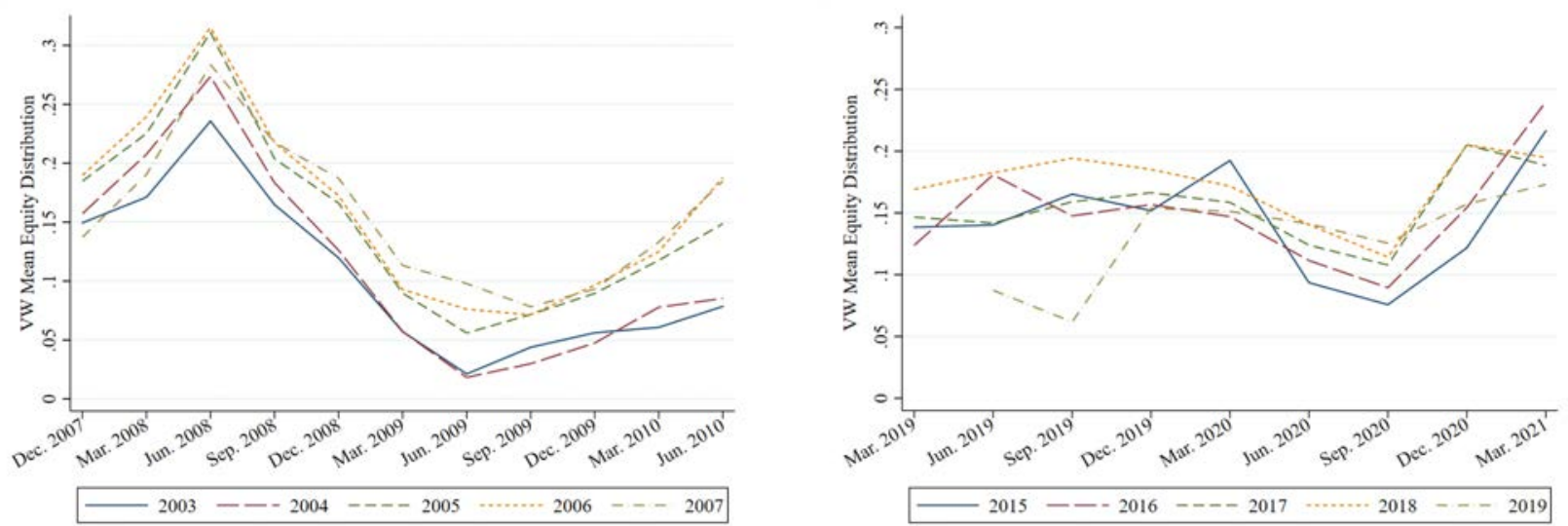
Figure 6: Counterfactual CLO Equity Distributions without Reinvestment or Refinancing

This figure presents realized equity distributions and counterfactual distributions without collateral reinvestment or refinancing of liabilities. Each panel presents the median equity distributions over time under the no-reinvestment (left-hand plot) and no-refinancing (right-hand plot) counterfactuals for the CLO 1.0 and 2.0 eras. CLO 1.0 refers to issuance from 1997 to 2009, while CLO 2.0 refers to issuance from 2010 onward. For the no-reinvestment case (Panel A), we compute counterfactual distributions assuming that loan spreads in the collateral pool are fixed, scaling collateral interest payments by the ratio of the counterfactual coupon rate to the realized coupon rate, then subtracting the reduction in collateral cash flows from the equity payout. For the no-refinancing case (Panel B), we compute counterfactual distributions assuming that tranche spreads are fixed, scaling debt tranche interest payments by the ratio of the counterfactual coupon rate to the realized coupon rate, then subtracting the additional debt tranche interest from the equity payout. Under both scenarios, a floor of zero is imposed on the counterfactual equity payout. The sample is restricted to vintage-quarter observations with at least five deals and at least $25 \%$ of the initial debt outstanding. Distributions and tranche information are from Intex.

Panel A: CLO 1.0 Deals
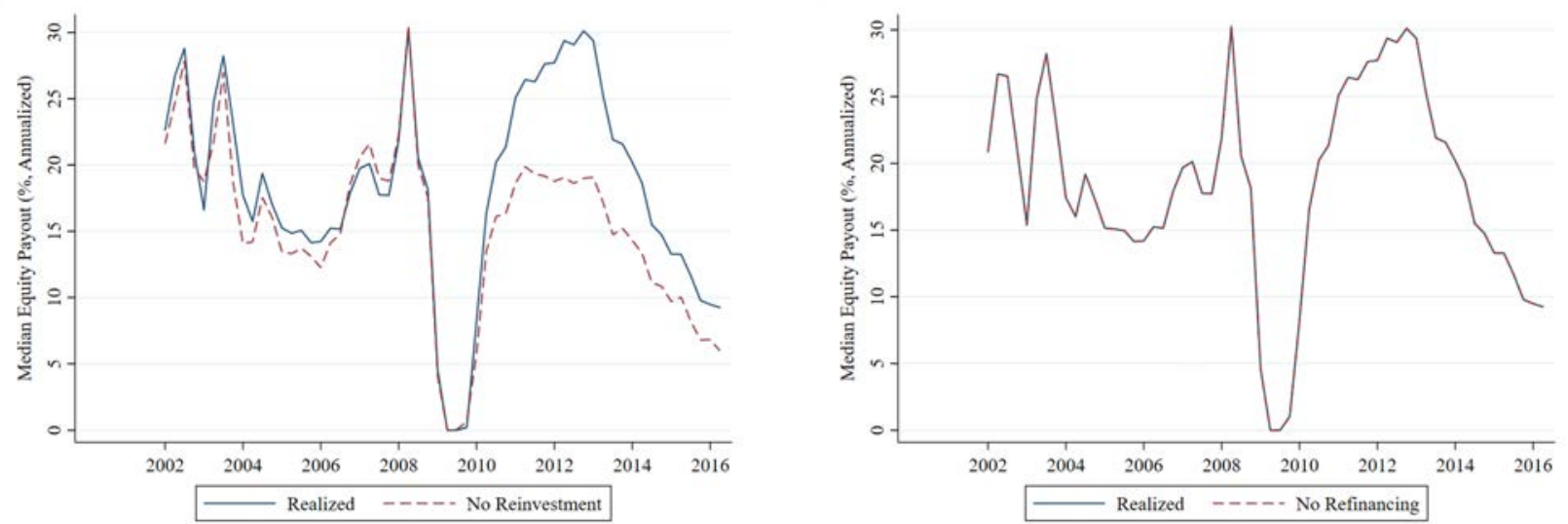

Panel B: CLO 2.0 Deals
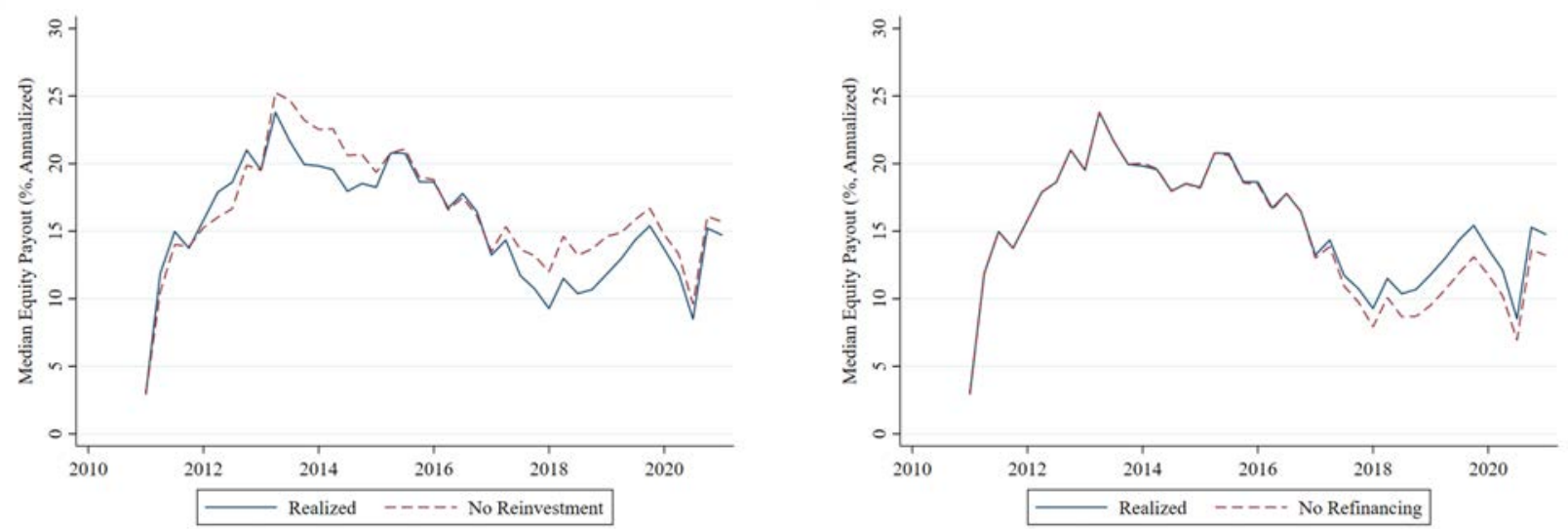


\section{Figure 7: Evolution of Loan Spreads over the CLO Life Cycle}

This figure presents the value-weighted average loan spread in CLO collateral pools by vintage group and calendar quarter after issuance. The three vintage groups are 2005-2009, 2010-2016, and 2017-2019. Each line in the plot is constructed as follows. We estimate a panel regression of loan spreads at the CLO level, weighting the individual loans in each collateral pool by their par value, on vintage group and calendar quarter fixed effects. The residuals from this regression provide a measure of deal-level loan spreads that is demeaned by issuance period, observation period, and time-invariant deal characteristics. We then organize the deal-quarter observations in event time by the number of quarters since issuance and compute the average residual for each vintage group and event quarter, weighting deals by their par balance.

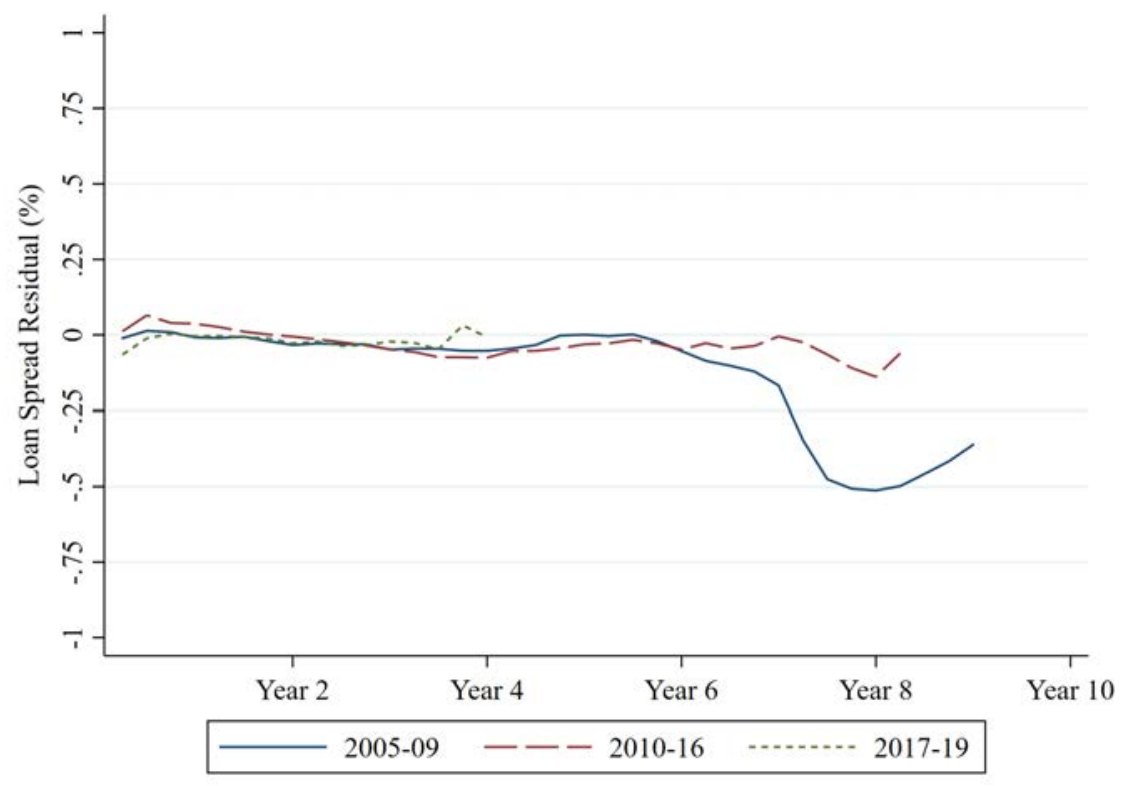




\section{Table 1: Sample Characteristics}

This table summarizes the CLO sample from Intex by deal vintage. Deal Count is the number of CLOs issued. Issuance Amount measures the aggregate dollar amount of CLOs issued. Both of these measures exclude refinancing and reset transactions. Mean Deal Size is the average initial deal balance. Mean Leverage Ratio is the average ratio of initial debt to deal balance. The last two columns report the number of deals with nonmissing data on equity and debt distributions and the number of such deals that have fully repaid the debt tranches, respectively. CLO 1.0 refers to issuance from 1997 to 2009, while CLO 2.0 refers to issuance from 2010 onward.

\begin{tabular}{|c|c|c|c|c|c|c|}
\hline Vintage & $\begin{array}{c}\text { Deal } \\
\text { Count }\end{array}$ & $\begin{array}{l}\text { Issuance } \\
\text { Amount } \\
(\$ \text { Bil. })\end{array}$ & $\begin{array}{c}\text { Mean } \\
\text { Deal Size } \\
(\$ \text { Mil. })\end{array}$ & $\begin{array}{c}\text { Mean } \\
\text { Leverage } \\
\text { Ratio }\end{array}$ & $\begin{array}{l}\text { Deals with } \\
\text { Nonmissing } \\
\text { Distributions }\end{array}$ & $\begin{array}{c}\text { Completed } \\
\text { Deals }\end{array}$ \\
\hline 1997-2002 & 30 & 14.8 & 436.5 & 0.922 & 20 & 19 \\
\hline 2003 & 31 & 13.2 & 424.6 & 0.916 & 25 & 25 \\
\hline 2004 & 65 & 30.5 & 469.2 & 0.909 & 49 & 49 \\
\hline 2005 & 99 & 48.6 & 490.6 & 0.906 & 80 & 79 \\
\hline 2006 & 175 & 90.0 & 514.3 & 0.907 & 153 & 151 \\
\hline 2007 & 169 & 95.7 & 566.3 & 0.908 & 150 & 148 \\
\hline 2008 & 41 & 30.6 & 745.8 & 0.909 & 28 & 27 \\
\hline 2009 & 5 & 4.7 & 944.6 & 0.905 & 2 & 2 \\
\hline 2010 & 12 & 4.5 & 372.5 & 0.903 & 11 & 10 \\
\hline 2011 & 30 & 14.6 & 487.6 & 0.901 & 27 & 27 \\
\hline 2012 & 114 & 53.0 & 465.3 & 0.898 & 113 & 93 \\
\hline 2013 & 171 & 85.1 & 497.7 & 0.896 & 167 & 63 \\
\hline 2014 & 239 & 128.4 & 537.3 & 0.893 & 237 & 74 \\
\hline 2015 & 192 & 103.1 & 536.8 & 0.893 & 190 & 26 \\
\hline 2016 & 171 & 82.3 & 481.1 & 0.894 & 169 & 13 \\
\hline 2017 & 197 & 114.1 & 579.0 & 0.893 & 192 & 1 \\
\hline 2018 & 272 & 143.0 & 525.9 & 0.893 & 267 & 0 \\
\hline 2019 & 252 & 121.8 & 483.5 & 0.893 & 251 & 1 \\
\hline CLO 1.0 & 615 & 328.1 & 533.4 & 0.903 & 507 & 500 \\
\hline CLO 2.0 & 1,650 & 849.9 & 515.1 & 0.888 & 1,624 & 308 \\
\hline Full Sample & 2,265 & $1,178.0$ & 520.1 & 0.892 & 2,131 & 808 \\
\hline
\end{tabular}


Table 2: Equity Performance of Completed CLO Deals

This table reports statistics on the performance of CLO equity by vintage. The sample contains completed deals that paid down $99 \%$ of their senior debt by March 2021. CLO 1.0 refers to issuance from 1997 to 2009, while CLO 2.0 refers to issuance from 2010 onward. Panel A reports internal rates of return, Panel B reports the public market equivalent (PME) versus the S\&P 500 Index, and Panel C reports the PME versus the S\&P 500 Banks sub-index. For the full sample PME estimates in Panels $\mathrm{B}$ and $\mathrm{C}$, we construct a $J$-test of the null hypothesis that the PME equals one using the spatial GMM covariance matrix from Korteweg and Nagel (2016), which accounts for correlated performance across deals by assuming that correlation declines with the degree of overlap in their time windows. ${ }^{*}, * *$, and ${ }^{* * *}$ denote $p$-values less than $0.10,0.05$, and 0.01 , respectively.

Panel A: Internal Rate of Return (\%)

\begin{tabular}{lcccccccr}
\hline Vintage & Mean & StDev & $\mathrm{p} 10$ & $\mathrm{p} 25$ & $\mathrm{p} 50$ & $\mathrm{p} 75$ & $\mathrm{p} 90$ & Obs. \\
\hline $1997-2002$ & 13.31 & 13.76 & 0.28 & 2.63 & 6.57 & 21.91 & 33.88 & 19 \\
2003 & 3.32 & 7.92 & -4.12 & -1.72 & 3.42 & 8.06 & 12.44 & 25 \\
2004 & 6.80 & 7.45 & -5.95 & 3.52 & 6.98 & 11.30 & 15.18 & 49 \\
2005 & 11.99 & 11.54 & 5.78 & 8.94 & 13.25 & 17.16 & 21.00 & 79 \\
2006 & 15.72 & 8.58 & 9.11 & 12.36 & 16.68 & 19.98 & 22.42 & 151 \\
2007 & 16.75 & 12.04 & 7.30 & 15.47 & 18.44 & 21.96 & 26.19 & 148 \\
2008 & 1.03 & 20.81 & -30.72 & -5.60 & 7.37 & 14.02 & 19.51 & 27 \\
$2009-2010$ & -0.66 & 18.64 & -32.52 & -5.53 & 4.92 & 11.68 & 14.54 & 12 \\
2011 & 12.54 & 11.61 & 3.16 & 8.38 & 14.12 & 19.70 & 22.60 & 27 \\
2012 & 7.81 & 9.07 & -0.97 & 5.02 & 8.37 & 12.71 & 16.59 & 93 \\
2013 & 5.38 & 11.50 & -5.64 & 2.15 & 5.79 & 9.63 & 18.44 & 63 \\
2014 & 0.13 & 10.21 & -16.39 & -7.16 & 1.42 & 7.37 & 11.15 & 74 \\
2015 & 1.13 & 12.96 & -16.58 & -7.36 & 4.60 & 10.22 & 14.83 & 26 \\
2016 & 2.22 & 13.06 & -15.19 & -1.58 & 4.52 & 12.05 & 15.58 & 13 \\
\hline CLO 1.0 & 12.95 & 12.26 & 1.71 & 8.73 & 15.16 & 19.75 & 23.51 & 500 \\
CLO 2.0 & 4.89 & 11.48 & -8.99 & 0.11 & 6.65 & 11.45 & 16.68 & 308 \\
Full Sample & 9.88 & 12.59 & -4.28 & 4.59 & 11.56 & 17.80 & 21.79 & 808 \\
\hline
\end{tabular}


Panel B: Public Market Equivalent versus S\&P 500

\begin{tabular}{lcccccccr}
\hline Vintage & Mean & StDev & p10 & p25 & p50 & p75 & p90 & Obs. \\
\hline $1997-2002$ & 1.50 & 0.69 & 0.74 & 0.88 & 1.40 & 1.84 & 2.37 & 19 \\
2003 & 0.91 & 0.31 & 0.61 & 0.75 & 0.85 & 1.06 & 1.28 & 25 \\
2004 & 1.11 & 0.38 & 0.61 & 0.90 & 1.03 & 1.26 & 1.58 & 49 \\
2005 & 1.48 & 0.45 & 1.04 & 1.22 & 1.47 & 1.77 & 2.04 & 79 \\
2006 & 1.76 & 0.55 & 1.21 & 1.44 & 1.76 & 2.04 & 2.27 & 151 \\
2007 & 2.03 & 0.60 & 1.32 & 1.79 & 2.06 & 2.35 & 2.69 & 148 \\
2008 & 1.11 & 0.55 & 0.34 & 0.70 & 1.15 & 1.53 & 1.75 & 27 \\
$2009-2010$ & 0.75 & 0.28 & 0.36 & 0.57 & 0.79 & 1.00 & 1.02 & 12 \\
2011 & 0.95 & 0.24 & 0.72 & 0.79 & 1.00 & 1.11 & 1.25 & 27 \\
2012 & 0.83 & 0.16 & 0.65 & 0.75 & 0.82 & 0.93 & 1.03 & 93 \\
2013 & 0.84 & 0.22 & 0.62 & 0.74 & 0.83 & 0.96 & 1.13 & 63 \\
2014 & 0.81 & 0.18 & 0.59 & 0.67 & 0.82 & 0.94 & 1.00 & 74 \\
2015 & 0.81 & 0.21 & 0.48 & 0.66 & 0.86 & 0.94 & 1.10 & 26 \\
2016 & 0.79 & 0.19 & 0.47 & 0.71 & 0.84 & 0.92 & 0.99 & 13 \\
\hline CLO 1.0 & $1.64^{* * *}$ & 0.64 & 0.83 & 1.20 & 1.66 & 2.05 & 2.37 & 500 \\
CLO 2.0 & $0.83^{* * *}$ & 0.20 & 0.59 & 0.72 & 0.84 & 0.96 & 1.07 & 308 \\
Full Sample & $1.33^{* * *}$ & 0.65 & 0.66 & 0.84 & 1.15 & 1.81 & 2.18 & 808 \\
\hline
\end{tabular}

Panel C: Public Market Equivalent versus Bank Stocks

\begin{tabular}{lcccccccr}
\hline Vintage & Mean & StDev & $\mathrm{p} 10$ & $\mathrm{p} 25$ & $\mathrm{p} 50$ & $\mathrm{p} 75$ & $\mathrm{p} 90$ & Obs. \\
\hline $1997-2002$ & 1.94 & 1.27 & 0.90 & 1.09 & 1.36 & 2.75 & 3.31 & 19 \\
2003 & 1.54 & 0.73 & 0.86 & 0.91 & 1.45 & 1.88 & 2.39 & 25 \\
2004 & 2.15 & 0.87 & 0.94 & 1.70 & 2.02 & 2.56 & 3.22 & 49 \\
2005 & 3.08 & 1.07 & 1.93 & 2.37 & 3.09 & 3.78 & 4.38 & 79 \\
2006 & 4.01 & 1.37 & 2.62 & 3.24 & 4.00 & 4.67 & 5.23 & 151 \\
2007 & 4.35 & 1.40 & 2.37 & 3.72 & 4.43 & 5.04 & 5.99 & 148 \\
2008 & 1.67 & 0.89 & 0.47 & 0.95 & 1.73 & 2.25 & 2.66 & 27 \\
$2009-2010$ & 0.78 & 0.31 & 0.38 & 0.60 & 0.75 & 1.07 & 1.10 & 12 \\
2011 & 0.87 & 0.24 & 0.61 & 0.70 & 0.90 & 1.07 & 1.16 & 27 \\
2012 & 0.80 & 0.16 & 0.63 & 0.71 & 0.78 & 0.90 & 1.00 & 93 \\
2013 & 0.83 & 0.22 & 0.61 & 0.71 & 0.80 & 0.93 & 1.09 & 63 \\
2014 & 0.80 & 0.17 & 0.61 & 0.68 & 0.81 & 0.91 & 0.97 & 74 \\
2015 & 0.80 & 0.19 & 0.52 & 0.64 & 0.84 & 0.95 & 1.00 & 26 \\
2016 & 0.70 & 0.16 & 0.44 & 0.64 & 0.70 & 0.81 & 0.89 & 13 \\
\hline CLO 1.0 & $3.44^{* * *}$ & 1.59 & 1.35 & 2.27 & 3.49 & 4.51 & 5.27 & 500 \\
CLO 2.0 & $0.81^{* * *}$ & 0.19 & 0.60 & 0.69 & 0.81 & 0.92 & 1.06 & 308 \\
Full Sample & $2.44^{* * *}$ & 1.79 & 0.68 & 0.85 & 1.93 & 3.92 & 4.84 & 808 \\
\hline
\end{tabular}




\section{Table 3: "Inside" Equity Performance of Completed CLO Deals}

This table reports statistics on the performance of "inside" CLO equity by era using gross of fee distributions. The sample contains completed deals that paid down $99 \%$ of their senior debt by March 2021. CLO 1.0 refers to issuance from 1997 to 2009, while CLO 2.0 refers to issuance from 2010 onward. Panel A reports internal rates of return, Panel B reports the public market equivalent (PME) versus the S\&P 500 Index, and Panel C reports the PME versus the S\&P 500 Banks subindex. For the PME estimates in Panels B and C, we construct a $J$-test of the null hypothesis that the PME equals one using the spatial GMM covariance matrix from Korteweg and Nagel (2016), which accounts for correlated performance across deals by assuming that correlation declines with the degree of overlap in their time windows. *, **, and *** denote $p$-values less than $0.10,0.05$, and 0.01 , respectively.

Panel A: Internal Rate of Return (\%)

\begin{tabular}{lcccccccc}
\hline Vintage & Mean & StDev & p10 & p25 & p50 & p75 & p90 & Obs. \\
\hline CLO 1.0 & 19.98 & 12.88 & 7.52 & 14.56 & 21.74 & 27.99 & 32.15 & 500 \\
CLO 2.0 & 10.92 & 11.79 & -2.28 & 6.07 & 12.49 & 17.56 & 22.51 & 308 \\
Full Sample & 16.53 & 13.22 & 2.30 & 10.48 & 17.97 & 25.26 & 30.53 & 808 \\
\hline
\end{tabular}

Panel B: Public Market Equivalent versus S\&P 500

\begin{tabular}{lcccccccc}
\hline Vintage & Mean & StDev & $\mathrm{p} 10$ & $\mathrm{p} 25$ & $\mathrm{p} 50$ & $\mathrm{p} 75$ & $\mathrm{p} 90$ & Obs. \\
\hline CLO 1.0 & $2.09^{* * *}$ & 0.82 & 1.06 & 1.54 & 2.05 & 2.66 & 3.06 & 500 \\
CLO 2.0 & $0.97^{* * *}$ & 0.22 & 0.72 & 0.85 & 0.98 & 1.09 & 1.20 & 308 \\
Full Sample & $1.66^{* * *}$ & 0.85 & 0.81 & 0.98 & 1.42 & 2.31 & 2.87 & 808 \\
\hline
\end{tabular}

Panel C: Public Market Equivalent versus Bank Stocks

\begin{tabular}{lcccccccc}
\hline Vintage & Mean & StDev & $\mathrm{p} 10$ & $\mathrm{p} 25$ & $\mathrm{p} 50$ & $\mathrm{p} 75$ & $\mathrm{p} 90$ & Obs. \\
\hline CLO 1.0 & $4.36^{* * *}$ & 2.03 & 1.65 & 2.82 & 4.36 & 5.86 & 6.81 & 500 \\
CLO 2.0 & $0.95^{* * *}$ & 0.22 & 0.70 & 0.82 & 0.95 & 1.07 & 1.19 & 308 \\
Full Sample & $3.06^{* * *}$ & 2.30 & 0.79 & 1.00 & 2.36 & 4.99 & 6.31 & 808 \\
\hline
\end{tabular}




\section{Table 4: GPME Analysis of CLO Performance}

This table presents estimates of the generalized public market equivalent (GPME) from Korteweg and Nagel (2016) for CLO equity, collateral, and debt tranches. The GPME is the expected sum of cash flows discounted using the SDF

$$
m_{t+h}^{h}=\exp \left(a h-b_{1} r_{m, t+h}^{h}-b_{2} r_{x, t+h}^{h}\right),
$$

where the parameters $a$ and $b$ are chosen to price the factor payoffs exactly. Cash flows are normalized to an initial investment of $\$ 1$. In each column, $r_{m}$ is the excess return of the CRSP valueweighted index. The remaining columns substitute the excess return on the following benchmarks for $r_{x, t+h}^{h}$ : the S\&P/LSTA U.S. Leveraged Loan 100 Index (LL), the Bloomberg-Barclays U.S. Corporate High Yield Bond Index (HY), the CBOE S\&P 500 Put-Write Index (PUT), and the value-weighted portfolio of primary dealer equities from He, Kelly, and Manela (2017) (HKM). Implied Equity is the weighted average of collateral and debt GPMEs implied by the balance sheet identity in equation (1). Standard errors of the SDF parameter estimates are in parentheses. We report $p$-values of the $J$-test that the GPME equals zero in brackets. ${ }^{*},{ }^{* *}$, and ${ }^{* * *}$ denote $p$-values less than 0.10, 0.05, and 0.01, respectively.

\begin{tabular}{|c|c|c|c|c|c|}
\hline & CAPM & $\mathrm{CAPM}+\mathrm{LL}$ & $\mathrm{CAPM}+\mathrm{HY}$ & $\mathrm{CAPM}+\mathrm{PUT}$ & HKM \\
\hline \multicolumn{6}{|c|}{ After-Fee GPME Estimates } \\
\hline \multirow[t]{2}{*}{ Equity } & $0.664^{* * *}$ & $0.573^{* * *}$ & $0.373^{* * *}$ & $0.573^{* * *}$ & $0.483^{* * *}$ \\
\hline & {$[0.000]$} & {$[0.000]$} & {$[0.000]$} & {$[0.000]$} & {$[0.000]$} \\
\hline \multirow[t]{2}{*}{ Collateral } & -0.033 & 0.050 & 0.036 & 0.001 & -0.061 \\
\hline & {$[0.722]$} & {$[0.232]$} & {$[0.709]$} & {$[0.988]$} & {$[0.274]$} \\
\hline \multirow[t]{2}{*}{ Debt Tranches } & -0.090 & 0.008 & 0.012 & -0.047 & -0.105 \\
\hline & {$[0.453]$} & {$[0.881]$} & {$[0.930]$} & {$[0.510]$} & {$[0.219]$} \\
\hline Implied Equity & 0.486 & 0.426 & 0.247 & 0.432 & 0.330 \\
\hline \multicolumn{6}{|c|}{ Before-Fee GPME Estimates } \\
\hline \multirow[t]{2}{*}{ Equity } & $1.106^{* * *}$ & $0.961^{* * *}$ & $0.685^{* * *}$ & $0.972^{* * *}$ & $0.892^{* * *}$ \\
\hline & {$[0.000]$} & {$[0.000]$} & {$[0.000]$} & {$[0.000]$} & {$[0.000]$} \\
\hline \multirow[t]{2}{*}{ Collateral } & 0.006 & $0.084^{* *}$ & 0.064 & 0.036 & -0.025 \\
\hline & {$[0.951]$} & {$[0.048]$} & {$[0.506]$} & {$[0.488]$} & {$[0.647]$} \\
\hline \multirow{2}{*}{ Debt Tranches } & -0.090 & 0.008 & 0.012 & -0.047 & -0.105 \\
\hline & {$[0.453]$} & {$[0.881]$} & {$[0.930]$} & {$[0.510]$} & {$[0.219]$} \\
\hline Implied Equity & 0.870 & 0.769 & 0.529 & 0.783 & 0.686 \\
\hline \multicolumn{6}{|c|}{ SDF Parameters } \\
\hline \multirow[t]{2}{*}{$a$} & -0.007 & -0.005 & -0.007 & -0.011 & -0.014 \\
\hline & $(0.003)$ & $(0.002)$ & $(0.003)$ & $(0.003)$ & $(0.004)$ \\
\hline \multirow[t]{2}{*}{$b_{1}$} & 2.284 & 0.217 & -1.572 & -0.435 & 4.708 \\
\hline & $(0.513)$ & $(0.559)$ & $(0.716)$ & $(1.229)$ & $(0.813)$ \\
\hline \multirow[t]{2}{*}{$b_{2}$} & & 2.301 & 3.670 & 3.985 & -1.893 \\
\hline & & $(0.471)$ & $(0.419)$ & $(1.691)$ & $(0.304)$ \\
\hline
\end{tabular}


Table 5: Counterfactual CLO Equity IRRs without Reinvestment or Refinancing

This table compares the realized performance of CLO equity to counterfactual performance without collateral reinvestment or refinancing of liabilities. For the no-reinvestment case (Panel A), we compute counterfactual distributions assuming that loan spreads in the collateral pool are fixed, scaling collateral interest payments by the ratio of the counterfactual coupon rate to the realized coupon rate, then subtracting the reduction in collateral cash flows from the equity payout. For the no-refinancing case (Panel B), we compute counterfactual distributions assuming that tranche spreads are fixed, scaling debt tranche interest payments by the ratio of the counterfactual coupon rate to the realized coupon rate, then subtracting the additional debt tranche interest from the equity payout. Under both scenarios, a floor of zero is imposed on the counterfactual equity payout. We report estimates of the generalized public market equivalent (GPME) from Korteweg and Nagel (2016) for CLO equity before and after fees under the realized and counterfactual scenarios, as well as the difference in GPMEs. Each column represents a different stochastic discount factor (SDF) specification described in the paper. We report $p$-values of the $J$-test that the GPME equals zero in brackets. ${ }^{*}, * *$, and ${ }^{* * *}$ denote $p$-values less than $0.10,0.05$, and 0.01 , respectively.

Panel A: No-Reinvestment Counterfactual

\begin{tabular}{lccccc}
\hline & CAPM & CAPM+LL & CAPM+HY & CAPM+PUT & HKM \\
\hline After-Fee GPME Estimates & & & & \\
Realized & $0.664^{* * *}$ & $0.573^{* * *}$ & $0.373^{* * *}$ & $0.573^{* * *}$ & $0.483^{* * *}$ \\
& {$[0.000]$} & {$[0.000]$} & {$[0.000]$} & {$[0.000]$} & {$[0.000]$} \\
No Reinvestment & $0.386^{* * *}$ & $0.365^{* * *}$ & $0.275^{* * *}$ & $0.338^{* * *}$ & $0.313^{* * *}$ \\
& {$[0.001]$} & {$[0.000]$} & {$[0.004]$} & {$[0.000]$} & {$[0.002]$} \\
Difference & 0.279 & 0.208 & 0.098 & 0.234 & 0.170 \\
Before-Fee GPME & Estimates & & & & \\
Realized & $1.106^{* * *}$ & $0.961^{* * *}$ & $0.685^{* * *}$ & $0.972^{* * *}$ & $0.892^{* * *}$ \\
& {$[0.000]$} & {$[0.000]$} & {$[0.000]$} & {$[0.000]$} & {$[0.000]$} \\
No Reinvestment & $0.834^{* * *}$ & $0.757^{* * *}$ & $0.589^{* * *}$ & $0.743^{* * *}$ & $0.734^{* * *}$ \\
& {$[0.000]$} & {$[0.000]$} & {$[0.000]$} & {$[0.000]$} & {$[0.000]$} \\
Difference & 0.272 & 0.203 & 0.096 & 0.229 & 0.158 \\
\hline
\end{tabular}

Panel B: No-Refinancing Counterfactual

\begin{tabular}{|c|c|c|c|c|c|}
\hline & CAPM & $\mathrm{CAPM}+\mathrm{LL}$ & $\mathrm{CAPM}+\mathrm{HY}$ & $\mathrm{CAPM}+\mathrm{PUT}$ & HKM \\
\hline \multicolumn{6}{|c|}{ After-Fee GPME Estimates } \\
\hline \multirow[t]{2}{*}{ Realized } & $0.664^{* * *}$ & $0.573^{* * *}$ & $0.373^{* * *}$ & $0.573^{* * *}$ & $0.483^{* * *}$ \\
\hline & {$[0.000]$} & {$[0.000]$} & {$[0.000]$} & {$[0.000]$} & {$[0.000]$} \\
\hline \multirow{2}{*}{ No Reinvestment } & $0.661^{* * *}$ & $0.566^{* * *}$ & $0.363^{* * *}$ & $0.567^{* * *}$ & $0.482^{* * *}$ \\
\hline & {$[0.000]$} & {$[0.000]$} & {$[0.000]$} & {$[0.000]$} & {$[0.000]$} \\
\hline Difference & 0.003 & 0.006 & 0.010 & 0.005 & 0.001 \\
\hline \multicolumn{6}{|c|}{ Before-Fee GPME Estimates } \\
\hline \multirow[t]{2}{*}{ Realized } & $1.106^{* * *}$ & $0.961^{* * *}$ & $0.685^{* * *}$ & $0.972^{* * *}$ & $0.892^{* * *}$ \\
\hline & {$[0.000]$} & {$[0.000]$} & {$[0.000]$} & {$[0.000]$} & {$[0.000]$} \\
\hline \multirow[t]{2}{*}{ No Reinvestment } & $1.103^{* * *}$ & $0.955^{* * *}$ & $0.675^{* * *}$ & $0.967^{* * *}$ & $0.893^{* * *}$ \\
\hline & {$[0.000]$} & {$[0.000]$} & {$[0.000]$} & {$[0.000]$} & {$[0.000]$} \\
\hline Difference & 0.002 & 0.006 & 0.010 & 0.005 & -0.001 \\
\hline
\end{tabular}


Table 6: Debt Tranche Performance of Completed CLO Deals

This table reports statistics on the performance of CLO debt tranches by initial rating category. The sample contains completed deals that paid down $99 \%$ of their senior debt by March 2021. CLO 1.0 refers to issuance from 1997 to 2009, while CLO 2.0 refers to issuance from 2010 onward. Panel A reports internal rates of return, while Panel B reports the PME versus synthetic floating-rate corporate bonds in the same rating category. Floating-rate corporate bond returns are based on swapping the fixed-rate cash flows using the maturity-matched swap rate at issuance. We explain the mark-to-market valuation of swapped bonds in the Internet Appendix. Each panel reports the performance of tranches by initial rating category, with the sample split into CLO 1.0 (before 2010), CLO 2.0 (2010 and later), and the full sample of completed deals (1997 to 2016). For the PME estimates in Panel B, we construct a $J$-test of the null hypothesis that the PME equals one using the spatial GMM covariance matrix from Korteweg and Nagel (2016), which accounts for correlated performance across deals by assuming that correlation declines with the degree of overlap in their time windows. ${ }^{*}, * *$, and $* * *$ denote $p$-values less than $0.10,0.05$, and 0.01 , respectively.

Panel A: Internal Rate of Return (\%)

\begin{tabular}{|c|c|c|c|c|c|c|c|c|}
\hline Vintage & Mean & StDev & p10 & $\mathrm{p} 25$ & $\mathrm{p} 50$ & $\mathrm{p} 75$ & p90 & Obs. \\
\hline \multicolumn{9}{|c|}{ CLO 1.0 (1997-2009) } \\
\hline AAA-Rated & 2.38 & 1.22 & 1.44 & 1.72 & 2.26 & 2.87 & 3.35 & 492 \\
\hline AA-Rated & 2.44 & 1.34 & 1.57 & 1.73 & 2.17 & 2.81 & 3.49 & 423 \\
\hline A-Rated & 2.99 & 2.65 & 1.95 & 2.14 & 2.72 & 3.74 & 4.43 & 479 \\
\hline BBB-Rated & 3.92 & 5.97 & 2.80 & 3.18 & 3.85 & 4.93 & 5.71 & 476 \\
\hline BB-Rated & 6.25 & 6.08 & 4.85 & 5.34 & 6.10 & 7.80 & 9.54 & 369 \\
\hline B-Rated & -1.64 & 34.53 & -63.30 & 7.16 & 9.64 & 11.49 & 22.20 & 6 \\
\hline \multicolumn{9}{|c|}{ CLO 2.0 (2010-2016) } \\
\hline AAA-Rated & 2.28 & 1.79 & 1.69 & 1.82 & 2.03 & 2.37 & 2.67 & 307 \\
\hline AA-Rated & 3.26 & 2.06 & 2.46 & 2.72 & 2.97 & 3.29 & 3.76 & 300 \\
\hline A-Rated & 4.01 & 1.81 & 3.26 & 3.48 & 3.77 & 4.12 & 4.75 & 298 \\
\hline BBB-Rated & 4.99 & 1.81 & 4.08 & 4.38 & 4.77 & 5.14 & 5.91 & 287 \\
\hline BB-Rated & 6.48 & 1.99 & 5.23 & 5.71 & 6.20 & 6.82 & 7.97 & 273 \\
\hline B-Rated & 7.27 & 2.60 & 5.98 & 6.33 & 6.93 & 7.55 & 8.24 & 95 \\
\hline \multicolumn{9}{|c|}{ Full Sample (1997-2016) } \\
\hline AAA-Rated & 2.34 & 1.47 & 1.53 & 1.78 & 2.12 & 2.63 & 3.26 & 799 \\
\hline AA-Rated & 2.78 & 1.72 & 1.63 & 2.01 & 2.66 & 3.13 & 3.58 & 723 \\
\hline A-Rated & 3.38 & 2.41 & 2.03 & 2.43 & 3.40 & 3.97 & 4.64 & 777 \\
\hline BBB-Rated & 4.32 & 4.87 & 2.95 & 3.56 & 4.39 & 5.07 & 5.81 & 763 \\
\hline BB-Rated & 6.35 & 4.78 & 4.99 & 5.49 & 6.15 & 7.23 & 9.02 & 642 \\
\hline B-Rated & 6.74 & 8.39 & 5.97 & 6.35 & 6.98 & 7.65 & 8.39 & 101 \\
\hline
\end{tabular}


Panel B: Public Market Equivalent versus Synthetic Floating-Rate Corporate Bonds

\begin{tabular}{lcccccccc}
\hline Vintage & Mean & StDev & $\mathrm{p} 10$ & $\mathrm{p} 25$ & $\mathrm{p} 50$ & $\mathrm{p} 75$ & $\mathrm{p} 90$ & Obs. \\
\hline CLO 1.0 (1997-2009) & & & & & & & \\
AAA-Rated & $1.03^{* * *}$ & 0.05 & 1.01 & 1.02 & 1.03 & 1.03 & 1.05 & 492 \\
AA-Rated & $1.05^{* * *}$ & 0.06 & 1.02 & 1.02 & 1.04 & 1.06 & 1.09 & 423 \\
A-Rated & $1.04^{* * *}$ & 0.07 & 0.98 & 1.00 & 1.03 & 1.06 & 1.11 & 479 \\
BBB-Rated & $1.09^{* * *}$ & 0.12 & 1.01 & 1.04 & 1.08 & 1.12 & 1.18 & 476 \\
BB-Rated & $1.20^{* * *}$ & 0.16 & 1.10 & 1.14 & 1.19 & 1.26 & 1.34 & 369 \\
B-Rated & $1.57^{* *}$ & 0.80 & 0.34 & 1.47 & 1.63 & 1.80 & 2.59 & 6 \\
CLO 2.0 (2010-2016) & & & & & & & \\
AAA-Rated & $1.02^{* * *}$ & 0.10 & 0.98 & 1.00 & 1.01 & 1.03 & 1.04 & 307 \\
AA-Rated & $1.06^{* * *}$ & 0.11 & 1.00 & 1.02 & 1.04 & 1.06 & 1.09 & 300 \\
A-Rated & $1.09^{* * *}$ & 0.11 & 1.02 & 1.06 & 1.08 & 1.10 & 1.14 & 298 \\
BBB-Rated & $1.10^{* * *}$ & 0.13 & 1.02 & 1.06 & 1.09 & 1.12 & 1.15 & 287 \\
BB-Rated & $1.05^{* * *}$ & 0.11 & 0.99 & 1.01 & 1.04 & 1.07 & 1.11 & 273 \\
B-Rated & $1.13^{* * *}$ & 0.22 & 1.04 & 1.07 & 1.10 & 1.14 & 1.20 & 95 \\
Full Sample & $1997-2016)$ & & & & & & & \\
AAA-Rated & $1.02^{* * *}$ & 0.07 & 0.99 & 1.01 & 1.02 & 1.03 & 1.04 & 799 \\
AA-Rated & $1.05^{* * *}$ & 0.08 & 1.01 & 1.02 & 1.04 & 1.06 & 1.09 & 723 \\
A-Rated & $1.06^{* * *}$ & 0.09 & 0.99 & 1.01 & 1.05 & 1.09 & 1.13 & 777 \\
BBB-Rated & $1.09^{* * *}$ & 0.12 & 1.01 & 1.04 & 1.08 & 1.12 & 1.17 & 763 \\
BB-Rated & $1.14^{* * *}$ & 0.16 & 1.01 & 1.04 & 1.12 & 1.21 & 1.29 & 642 \\
B-Rated & $1.16^{* * *}$ & 0.30 & 1.03 & 1.07 & 1.10 & 1.14 & 1.27 & 101 \\
\hline
\end{tabular}




\section{Table 7: Default Rates for CLO Tranches and Corporate Bonds}

This table summarizes the default rates of CLO tranches and corporate bonds issued between 1997 and 2019. Panel A is based on the CLO 1.0 era, covering issuances from 1997 to 2009, while Panel B is based on the CLO 2.0 era, covering issuances from 2010 to 2019. Default Rate is the percentage of issues with an initial rating in a given category that defaulted. Num. Issues is the number of individual bonds (i.e., CUSIPs) issued in a given category during the sub-period. Note that the number of CLO tranches is higher than reported in the paper because calculations in the paper are done at the deal-level and combine tranches that are refinanced or reissued. We observe CLO tranche defaults through March 2021 using reports from Moody's (2020) and Standard \& Poor's $(2014,2021)$. Corporate bond defaults are from Mergent Fixed Income Securities Database (FISD), which has default data through September 2020. The sample of corporate bonds includes corporate debentures and convertibles that were rated by Moody's or Standard \& Poor's. Rating categories are based on the $\mathrm{S} \& \mathrm{P}$ rating, unless $\mathrm{S} \& \mathrm{P}$ did not rate the bond, in which case we use the Moody's rating. We combine the BB and B categories because there are few CLO tranches issued in the B category.

Panel A: CLO 1.0 Era (1997-2009)

\begin{tabular}{lccccc}
\hline & \multicolumn{2}{c}{ CLO Tranches } & & \multicolumn{2}{c}{ Corporate Bonds } \\
\cline { 2 - 3 } Rating & Default Rate (\%) & Num. Issues & & Default Rate (\%) & Num. Issues \\
\hline AAA & 0 & 1,250 & & 0.28 & 352 \\
AA & 0 & 531 & & 0.29 & 1,377 \\
A & 0.30 & 661 & & 2.75 & 3,568 \\
BBB & 1.62 & 680 & & 3.48 & 4,892 \\
BB/B & 3.33 & 481 & 9.31 & 7,391 \\
\hline
\end{tabular}

Panel B: CLO 2.0 Era (2010-2019)

\begin{tabular}{lccccc}
\hline & \multicolumn{2}{c}{ CLO Tranches } & & \multicolumn{2}{c}{ Corporate Bonds } \\
\cline { 2 - 3 } Rating & Default Rate $(\%)$ & Num. Issues & & Default Rate (\%) & Num. Issues \\
\hline AAA & 0 & 4,779 & & 0 & 150 \\
AA & 0 & 3,671 & & 0.41 & 775 \\
A & 0 & 3,122 & & 0.76 & 3,906 \\
BBB & 0 & 2,769 & & 6.16 & 5,675 \\
BB/B & 0 & 3,134 & & & 5,471 \\
\hline
\end{tabular}


Table 8: Collateral Performance of Completed CLO Deals

This table reports statistics on the performance of CLO collateral by era. The sample contains completed deals that paid down $99 \%$ of their senior debt by March 2021. CLO 1.0 refers to issuance from 1997 to 2009, while CLO 2.0 refers to issuance from 2010 onward. Panel A reports the beforefee public market equivalent (PME) versus the S\&P/LSTA U.S. Leveraged Loan 100 Index, with before-fee collateral cash flows estimated as the sum of estimated management fees and after-fee distributions to all CLO tranches. Panel B reports the after-fee PME versus a value-weighted portfolio of loan mutual funds, with after-fee collateral cash flows estimated as the sum of afterfee distributions to all CLO tranches. For the PME estimates, we construct a $J$-test of the null hypothesis that the PME equals one using the spatial GMM covariance matrix from Korteweg and Nagel (2016), which accounts for correlated performance across deals by assuming that correlation declines with the degree of overlap in their time windows. ${ }^{*}, * *$, and ${ }^{* * *}$ denote $p$-values less than $0.10,0.05$, and 0.01 , respectively.

Panel A: Before-Fee Public Market Equivalent versus LSTA Index

\begin{tabular}{lcccccccc}
\hline Vintage & Mean & StDev & p10 & p25 & p50 & p75 & p90 & Obs. \\
\hline CLO 1.0 & $0.97^{* *}$ & 0.27 & 0.92 & 0.94 & 0.97 & 0.99 & 1.03 & 500 \\
CLO 2.0 & $0.98^{* * *}$ & 0.10 & 0.94 & 0.96 & 0.97 & 0.99 & 1.03 & 308 \\
Full Sample & $0.98^{* * *}$ & 0.22 & 0.92 & 0.95 & 0.97 & 0.99 & 1.03 & 808 \\
\hline
\end{tabular}

Panel B: After-Fee Public Market Equivalent versus Loan Mutual Funds

\begin{tabular}{lcccccccc}
\hline Vintage & Mean & StDev & $\mathrm{p} 10$ & $\mathrm{p} 25$ & $\mathrm{p} 50$ & $\mathrm{p} 75$ & $\mathrm{p} 90$ & Obs. \\
\hline CLO 1.0 & 1.03 & 0.26 & 0.98 & 1.00 & 1.03 & 1.05 & 1.08 & 499 \\
CLO 2.0 & 1.00 & 0.10 & 0.96 & 0.98 & 0.99 & 1.01 & 1.04 & 308 \\
Full Sample & 1.02 & 0.22 & 0.96 & 0.99 & 1.01 & 1.04 & 1.08 & 807 \\
\hline
\end{tabular}

